\title{
Equilibrium Subprime Lending
}

\author{
Igor Makarov* and Guillaume Plantin ${ }^{\dagger \ddagger}$
}

January 2009

\begin{abstract}
This paper studies a market for secured loans to information-problematic borrowers. Competitive banks grant mortgages to households to finance a fixed supply of homes. There are two contracting frictions: households privately observe their endowments, and they cannot commit to a contract. Banks can commit to eviction after payment default. Households honor contractual repayments as long as i) they can afford it, and ii) they prefer to do so rather than exercise endogenous outside options in mortgage and housing markets. Loan-to-income ratios, home prices, trading volume in the housing market, and default rates are joint equilibrium outcomes that we characterize in quasi-closed forms. Both the systematic and idiosyncratic components of income risk reduce debt capacities, albeit through quite distinct channels. Thus, the net impact of the diversifiability of income risk on mortgage capacity and home prices is ambiguous. The paper also shows that these contracting frictions rule out some types of rational bubbles that would be sustainable in a frictionless economy, and studies the impact of bubbly equilibrium price paths on mortgage terms.
\end{abstract}

Keywords:

JEL classification:

*London Business School. E-mail: imakarov@london.edu.

${ }^{\dagger}$ London Business School. E-mail: gplantin@london.edu.

${ }^{\ddagger}$ We thank Joao Cocco, Harold Cole, Stéphane Guibaud, Margaret Kyle, Oleg Rytchkov, Harald Uhlig, Vikrant Vig, and participants in various seminars for very helpful comments. 


\section{Introduction}

Common financing contracts feature fewer contingencies than risk sharing in frictionless markets would predict. In particular, households and small businesses typically enter into debt contracts with noncontingent repayment schedules and costly resolution of defaults. A vast literature, pioneered by Townsend (1979) and Gale and Hellwig (1985), construes these arrangements as a consequence of costly state verification. Namely, such contracts may be optimal if the lender incurs a cost to observe the realization of the pledged cash flows, while the borrower does not. This paper studies how this ex post informational asymmetry impacts asset prices in a dynamic endowment economy. Following the 2007 mortgage default crisis, a recent empirical literature highlights the important role of contracting frictions in the subprime mortgage market. ${ }^{1}$ This paper offers a parsimonious model in which contracting frictions jointly determine financing capacities and asset prices. The model is analytically tractable and delivers realistic orders of magnitude for debt capacities, default intensities, and trading volume in subprime mortgage markets.

We study an economy in which banks competitively grant mortgages to households so as to finance a fixed supply of homes. A mortgage is a claim to a household's future income and to the future market value of its home. Households are myopic, and simply seek to maximize the size of their current homes subject to some moving costs. Thus, households are tightly contrained in the sense that they always exhaust their financing capacities when they buy new homes. ${ }^{2}$ Two contracting frictions determine this capacity. First, households privately observe their incomes, and can secretly consume all or part of it before reporting the residual to a lender. Second, households cannot commit to a contract. They are free to leave a current relationship, and re-trade in mortgage and housing markets as they see fit. Banks can commit to eviction after payment default. The threat of eviction creates some incentives for households to repay. In equilibrium, a household honors payments as long as two conditions are met. First, its income must be sufficiently high that it can repay. Second, market conditions must be such that the household wants to repay instead of terminating the mortgage, vacating the home, and re-trading in mortgage and housing markets. Households' aggregate debt capacity drives the aggregate demand for homes. Home supply at a given

\footnotetext{
${ }^{1}$ See, e.g., Keys et al. (2008) or Mian and Sufi (2008).

${ }^{2}$ Rochet (2007) makes a similar assumption in the different context of sovereign borrowing.
} 
date stems from foreclosures after default, sales motivated by the acquisition of a larger home, and sales that follow exogenous moving decisions. Market-clearing home prices in turn drive aggregate demand.

The assumption of tightly constrained agents who exhaust their mortgage capacity is meant to describe a housing market in an area that is populated by many subprime borrowers, and/or is subject to strong supply constraints. Mian and Sufi (2008) find evidence consistent with binding borrowing constraints in geographical areas with an important population of subprime borrowers. This assumption allows us to characterize equilibrium loan-to-income ratios, home prices, default intensities, and turnover in the housing market.

We obtain the following main results. First, systematic income risk has a negative impact on debt capacity because it implies that evictions are more likely to take place when home demand is low. This lowers the endogenous collateral value of homes, which in turn generates low current debt capacities and home prices. This result is different from one of financial amplification in which a low collateral value of assets generates productive or allocative inefficiencies (see, e.g., Bernanke and Gertler, 1989, or Kiyotaki and Moore, 1997). In our economy, agents do not create real externalities for each other through the balance-sheet channel. The competitive equilibrium is allocationally efficient.

Second, if all else equal a larger fraction of individual income risk is idiosyncratic, then equilibrium debt capacities and home prices are not necessarily higher. The intuition is the following. If a larger fraction of total income risk is idiosyncratic, then the income of a particular household is less correlated with home prices. On one hand, this raises banks' proceeds from foreclosures. This mitigates the aforementioned problem of endogenous low liquidation values. On the other hand, diversification of income risk also makes households' lack of commitment power more costly. Households with positive idiosyncratic income shocks have a low probability of default. But they eventually seek to move for exogenous reasons, or to climb up the property ladder since they moved up in the cross-section of incomes. As a result, they exit the contractual relationship when the net present value of continuation is the highest to the incumbent bank. Households' lack of commitment is less costly in the presence of more systematic income risk. In this case, a household which experiences positive income shocks competes in mortgage and housing markets with households with similarly 
high income realizations. Thus, termination is less valuable to the household, and less costly to its bank. Whether the net impact of diversification of income risk on equilibrium debt capacities is positive or negative depends on the parameters.

In other words, we establish that in the presence of one-sided commitment, collateralized lending is not necessarily eased by the diversifiability of borrowers' income risk. The larger ex post heterogeneity of borrowers implied by diversifiability is a double-edged sword. On one hand, the assets seized from unlucky borrowers can always be sold to luckier borrowers standing ready to snap them up. But the flip side of these higher liquidation proceeds is that these same lucky borrowers receive more outside options in equilibrium. They also impose more costs on their banks when they exercise these options. The possible benefits from diversification on collateral liquidity have been well identified in the literature on endogenous debt capacities (see, e.g., Shleifer and Vishny, 1992). That these benefits may be more than offset by the costs induced by borrowers' endogenous outside options is a novel finding, to our knowledge.

We establish these first two results under the assumptions that the equilibrium price is linear in aggregate income, and that contractual mortgage repayments are constant. Our third result is that the linear equilibrium is the unique equilibrium in which home prices satisfy a transversality condition. We also show that some types of rational bubbles that can be sustained in unconstrained economies are no longer feasible equilibrium outcomes in the presence of noncontingent contracts. We show that "bubbly" equilibrium price paths imply equilibrium mortgage payments that are lower than with non-bubbly prices. Aggregate income shocks have a more persistent impact on defaults in the presence of a bubbly price path because contractual repayment-to-income ratios are countercyclical in this case.

Finally, we study contracts with more complex repayment schedules than the fixedrepayment ones used throughout the paper. We find that contracts with initial "teaser rates" that gradually increase are optimal for a plausible range of parameters. We also find that these contracts do not generate significantly larger debt capacities than the simple fixed-repayment ones.

This paper relates to two strands of literature - the literature on endogenous incomplete markets and the literature on the microeconomics of housing markets. First, a large body 
of work seeks to endogenize market incompleteness with commitment problems (see, e.g., Alvarez and Jermann (2000), Kehoe and Levine (2001), and Hellwig and Lorenzoni (2008) for recent contributions). Closest to our approach, Krueger and Uhlig (2005) introduce in this literature the feature that households' outside options after terminating a contract are competitively supplied by the financial sector - a key ingredient of our model. Although we have a more applied focus than these contributions, we share with them the broader goal of characterizing the equilibrium interaction between individual contracting problems and asset prices. We depart from these papers in that our primitive contracting friction is ex post private information. This friction entails that contractual repayments are noncontingent, and that households with bad outside options unwittingly default in equilibrium. Predicting these two realistic features of debt markets is impossible for models in which limited commitment is the sole contracting problem.

Stein (1995) and Ortalo-Magné and Rady (2006) study the impact of credit constraints on prices and trading volume in housing markets. Both papers assume realistic but exogenous credit constraints, and write a detailed model of households' decision-making under such constraints. Our analysis is complementary. Our broad-brush approach is more stylized. It abstracts from important features of housing markets such as interest rate risk and the role of downpayments. However, contracts and credit constraints are endogenous. Piskorski and Tchistyi (2008) study optimal mortgages in the presence of an income diversion problem similar to ours. They solve for an optimal recursive contract in a much richer contracting environment than ours, but consider exogenous home values.

Finally, even though our focus is on the qualitative analysis of a stylized model, we obtain plausible orders of magnitude for equilibrium variables. This suggests that our setup is a promising workhorse for more quantitative future work on mortgage markets, along routes that we discuss in the conclusion.

\section{Model}

Time is continuous and is indexed by $t \in[0,+\infty)$. We fix a filtered probability space $(\Omega, \mathcal{F}, P)$. There is a single perishable consumption good which serves as the numéraire. There is a unit mass of assets - housing units. There are two types of agents: banks and a 
unit mass of households. Each housing unit can be occupied by at most one household, but not by banks. A household can occupy several units. The rights to trade vacant units are contractible.

\section{Banks}

Banks are infinitely lived, risk-neutral, and discount the future at the rate $r>0$. They compete for financing contracts to the households. Banks have an aggregate endowment that we assume to be always larger than households' equilibrium borrowing capacity.

Banks own an eviction technology. This means that a bank can transform an occupied home that it has financed into a vacant home. Eviction comes at a cost equal to a fraction $\lambda$ of the home market value, where $\lambda \in[0,1]$. This captures the value loss implied by foreclosures.

\section{Households}

Each household is endowed with a stream of disposable income that it would like to invest entirely in the housing market. Contracting frictions described below frustrate this objective. Formally, every household $j \in[0,1]$ is endowed with an income stream $\left(I_{j, t}\right)_{t \geq 0}$ such that

$$
I_{j, t}=I_{t} \times i_{j, t} .
$$

The systematic component of income obeys

$$
\frac{d I_{t}}{I_{t}}=\phi \sigma d W_{t}
$$

where $W_{t}$ is a standard Brownian motion ${ }^{3}, \phi \in[0,1]$, and $\sigma>0$. We set $I_{0}=1$.

Idiosyncratic income follows a geometric Brownian motion that is re-set at random dates generated by a Poisson process. Formally, for all $j \in[0,1]$, there exists a Poisson process $N_{j, t}$ with intensity $\delta>0$ and realization dates $\aleph_{j}=\left(T_{j, k}\right)_{k \in \mathbb{N}}$ such that

$$
\left\{\begin{array}{c}
\forall k \in \mathbb{N}, i_{j, T_{j, k}}=1 \\
\forall k \in \mathbb{N}, T_{j, k}<t<T_{j, k+1} \rightarrow \frac{d i_{j, t}}{i_{j, t}}=\sqrt{1-\phi^{2}} \sigma d W_{j, t}
\end{array},\right.
$$

where $W_{j, t}$ is a standard Brownian motion. All stochastic processes are pairwise independent.

This exponential stopping and re-setting of idiosyncratic income processes implies that

\footnotetext{
${ }^{3}$ It is easy to extend the whole analysis to the case of a Brownian motion with constant drift.
} 
idiosyncratic incomes $\left(i_{j, t}\right)_{j \in[0,1]}$ have a constant cross-sectional distribution. At each resetting date, households terminate the current contractual relationship, leave their current home, and occupy a new one for unmodelled reasons. These dates capture trades in the housing market that are not primarily driven by the evolution of the real estate market, but rather by occupational changes, changes in marital status, death, etc. ${ }^{4}$ In the remainder of the paper, we refer to these dates as exogenous termination dates or ET dates.

We will apply the exact law of large numbers to this continuum of independent processes. As is well known, doing so in a mathematically correct fashion requires the construction of an extension of the product of the Lebesgue unit interval and the state space such that the continuum of random variables be measurable with respect to this extension. Sun and Zhang (2008) show the existence of such extensions in which the exact law of large numbers applies for any variety of distributions. For expositional simplicity, we will informally invoke the exact law of large numbers throughout without explicitly constructing such complex mathematical objects.

At each date, households can secretly consume all or part of their income before reporting the residual. Households are tightly constrained in the sense that their objective is to maximize the size of the homes that they currently occupy subject to switching costs. Formally, household $j$ first solves at each date $t$ the following program:

$$
\begin{aligned}
& \operatorname{Max}_{q_{j, t}}\left\{q_{j, t}-c \times 1_{\left\{t \notin \aleph_{j}\right\}} \times q_{j, t_{-}}\right\} \\
& \text {s.t. } q_{j, t} P_{t} \leq F_{j, t}
\end{aligned}
$$

where $q_{j, t}$ is the size of the home - the number of housing units - that household $j$ occupies at date $t, F_{j, t}$ denotes the total funds that household $j$ can obtain from banks at date $t, P_{t}$ is the price at which the housing market clears, $\aleph_{j}$ is the set of ET dates, and $c>0$. The switching cost induced by $c$ captures all the costs associated with moving, mortgage refinancings, etc. Household $j$ then chooses the maximal date- $t$ consumption compatible with the optimal $q_{j, t}$ in (1.1). Negative consumption is not feasible.

We also assume that when households are indifferent between switching home or not, they

\footnotetext{
${ }^{4}$ That exogenous moving decisions and re-setting of idiosyncratic incomes are contemporaneous simplifies the analysis but is not crucial to our results.
} 
choose not to.

\section{Market for vacant homes}

Vacant homes trade in a Walrasian market: banks and households are home-price takers. The market price is not contractible. This assumption captures that the residential housing supply is comprised in practice of heterogenous units. Thus, using a broad housing price index as a contracting variable for the financing of a given unit would not be very helpful. Indexed mortgages are rare to the best of our knowledge. The alternative assumption that market price is contractible is also interesting. We study it in Section 2.2.4.

\section{Market for financing contracts}

Banks can fully commit to a contract with a household and can enforce exclusivity. Households cannot commit to a contract: they are free to leave their home and terminate a relationship with a bank as they see fit. A loan contract specifies the amount initially lent to a household for the acquisition of vacant units, and the future repayments and eviction decisions associated with the income path reported by this household. We restrict the analysis to eviction decisions that are a deterministic function of the household's report. ${ }^{5}$ Recall that households are myopic and can conceal income at no cost, so that only the threat of eviction can generate repayments. Given this simple contracting environment, repayments are noncontingent. The bank retains the rights to sell the home once it is vacant, and commits to evict a household which does not meet a contractual repayment. Given that banks and households have linear preferences, we make the natural assumption that banks compete along loans per unit of income. More precisely, banks simultaneously quote at each date a loan-to-income ratio $l$ and an associated repayment schedule for a unit income, thereby committing to grant to a household who reports a current income $I$ a loan $L=l \times \frac{I}{r}$ against future repayments that are also scaled by $I$. If several banks make competitive offers, they obtain equal market shares.

In equilibrium, banks make no profits, households solve (1.1), and markets for vacant homes and for contracts clear at each date. The assumption that households exhaust their current borrowing capacity greatly simplifies the analysis. Solving for explicit equilibrium

\footnotetext{
${ }^{5}$ This restriction is similar to the restriction to deterministic auditing schemes in applications of costly state verification such as Bernanke and Gertler (1989) or Gale and Hellwig (1985). A key factor in the design of contracts that would allow for randomized eviction would be households' rates of substitution of consumption for housing services. Our model in which this rate is infinite is not appropriate for the analysis of such contracts. Randomized eviction seems difficult to implement in practice in mortgage markets.
} 
contracts and prices in this general environment remains difficult, however, for two reasons. First, contractual repayments cannot be made contingent on income, but can be made contingent on time, with possibly complex schedules. Second, the supply and demand of vacant homes at a given date depends on all past contracts and on the past re-allocations of homes between ex post heterogeneous households with time-varying borrowing capacities. The balance of the paper solves the model in various special cases. Sections 2 and 3 restrict the analysis to the case in which banks offer contracts with constant repayments. Section 2 studies equilibria in which prices are a linear function of aggregate income. Section 3 studies nonlinear prices. Section 4 discusses time-contingent repayment schemes. Section 5 concludes. Proofs with little economic content are relegated to an appendix in Section 6.

\section{Constant Repayments and Linear Prices}

This section solves for equilibria under the restrictions that banks offer contracts with constant repayments, and that prices are a linear function of aggregate income. Under the restriction to fixed-repayment contracts, a contract is characterized by a loan-to-income ratio and a repayment ratio $\kappa \in(0,1)$ such that the contractual repayment offered to a household reporting an income $I$ is equal to $\kappa I$ per unit of time for the duration of the contract. The contractual terms that a bank quotes at date $t$ can, of course, depend on all the information available at $t$. We first solve for the polar cases in which $\phi=0$ and $\phi=1$, and compare the equilibrium debt capacities obtained in each case. We then tackle the case in which $\phi \in(0,1)$.

\subsection{Non-Diversifiable Income Risk}

This section solves the model in the simplest case in which $\phi=1$. Income processes are ex post identical in this case. We assume that housing units are evenly distributed across households at the outset. This case is particularly simple because trades in the housing market follow only two motives: the occurence of an ET date and default. Absent crosssectional heterogeneity, there is no other reason for going on the market since there is no possibility to move along the property ladder. Proposition 1 characterizes the unique linear equilibrium. 


\section{Proposition 1}

Let

$$
\begin{aligned}
\alpha & =\sqrt{\frac{2(r+\delta)}{\sigma^{2}}+\frac{1}{4}}-\frac{1}{2}, \\
\rho & =1-\lambda\left(1+\frac{\delta}{r}\right) .
\end{aligned}
$$

There is a unique equilibrium with fixed-repayment contracts and linear home prices. The repayment offered to household $j$ at date $t$ is $\kappa \times I_{t}$, where the constant $\kappa$ is the unique solution within $(0,1)$ of:

$$
(\alpha+1) \kappa^{\alpha}=1+\rho \alpha \kappa^{\alpha+1} .
$$

The price of a home unit is:

$$
P_{t}=\frac{1-\kappa^{\alpha}}{1-\rho \kappa^{\alpha+1}} \times \frac{\kappa I_{t}}{r}=\frac{\alpha}{\alpha+1} \times \frac{\kappa I_{t}}{r},
$$

where $\frac{\kappa \alpha}{\alpha+1}$ is also the loan-to-income ratio offered in the loan market.

Proof. We need to solve for the loan-to-income ratio and for the repayment ratio $\kappa$ that a bank chooses to offer at date $t$ under the expectation that future home prices will satisfy

$$
\forall u \geq 0, P_{t+u}=P I_{t+u}
$$

for some constant $P>0$. A loan taken by household $j$ at date $t$ is terminated at the random date $t+T^{j, t}$, where

$$
T^{j, t}=\min \left(T_{\delta}^{j, t}, T_{\kappa}^{j, t}\right)
$$

The random variable $T_{\delta}^{j, t}$ is the first ET date occuring after $t$ :

$$
T_{\delta}^{j, t}=\min \aleph_{j} \cap(t,+\infty),
$$

and $T_{\kappa}^{j, t}$ denotes the time elapsed until the income of household $j$ hits the value $\kappa I_{j, t}$ for the first time after $t$. Namely, 


$$
\begin{aligned}
T_{\kappa}^{j, t} & =\min \left\{\tau: I_{j, t+\tau}=\kappa I_{j, t}\right\} \\
& =\min \left\{\tau: W_{t+\tau}-W_{t}=\frac{\ln \kappa}{\sigma}+\frac{\sigma \tau}{2}\right\} .
\end{aligned}
$$

The random variables $T^{j, t}, T_{\delta}^{j, t}, T_{\kappa}^{j, t}$ are stopping times adapted to $\left(\mathcal{F}_{t}\right)_{t \geq 0}$. Since their distributions do not depend on $j$ and depend on $t$ only through $\kappa$, we will omit the superscripts $j, t$ on these variables in what follows.

It is in the interest of a household to fully disclose its income $I_{j, t}=I_{t}$ at the outset of a date- $t$ contract in order to obtain the largest possible home. Thus, if a household $j$ accepts the offer from a bank that quotes a repayment ratio $\kappa$ at date $t$, the bank expects the future flows from lending to household $j$ to be equal to

$$
L_{j, t}=E_{t}\left(\int_{t}^{t+T} e^{-r s} \kappa I_{j, t} d s+(1-\lambda) e^{-r T_{\kappa}} 1_{\left\{T_{\delta}>T_{\kappa}\right\}} P_{t+T_{\kappa}} q_{j, t}+1_{\left\{T_{\delta} \leq T_{\kappa}\right\}} e^{-r T_{\delta}} P_{t+T_{\delta}} q_{j, t}\right),
$$

where $q_{j, t}$ is the number of home units purchased by household $j$ at date $t$. The first term on the right-hand side of (2.4) is the expected value of repayments before termination. The second term is the expected proceeds from a home sale net of eviction costs. The third term is the expected proceeds from selling an unoccupied home after an ET date.

Let $\Delta_{t} \subset[0,1]$ denote the subset of households who switch homes between $t$ and $t+d t$. Let $s_{t} d t$ denote the measure of vacant homes supplied in the market between $t$ and $t+d t$. Competitive offers generate total expected repayments of

$$
\int_{\Delta_{t}} L_{j, t} d j=\int_{\Delta_{t}} d j \times E_{t}\left(\int_{t}^{t+T} e^{-r s} \kappa I_{t} d s\right)+s_{t} \times E_{t}\left[\begin{array}{c}
(1-\lambda) e^{-r T_{\kappa}} 1_{\left\{T_{\delta}>T_{\kappa}\right\}} P_{t+T_{\kappa}} \\
+1_{\left\{T_{\delta} \leq T_{\kappa}\right\}} e^{-r T_{\delta}} P_{t+T_{\delta}}
\end{array}\right]
$$

Both $\Delta_{t}$ and $s_{t}$ depend in a complex fashion on income history. That each household always trades one unit implies, however, that

$$
\forall t, s_{t}=\int_{\Delta_{t}} d j
$$


Plugging the conjectured linear price (2.3) in (2.5) and applying Lemma 1 in Section 6.1 with $\phi=1$ and $\nu=0,(2.5)$ becomes:

$$
\int_{\Delta_{t}} L_{j, t} d j=s_{t}\left(\frac{\kappa\left(1-\kappa^{\alpha}\right)}{r+\delta}+\left((1-\lambda) \kappa^{\alpha+1}+\frac{\delta\left(1-\kappa^{\alpha+1}\right)}{r+\delta}\right) P\right) I_{t} .
$$

The equilibrium repayment ratio $\kappa$ must maximize $\int_{\Delta_{t}} L_{j, t} d j$. The equilibrium loan-toincome ratio yields zero profit to banks for such a $\kappa$. From (2.7) it is easy to see that the optimal $\kappa$ is a constant such that

$$
(1+\alpha)(1-r \rho P) \kappa^{\alpha}=1 .
$$

Clearing the market for vacant homes yields

$$
s_{t} \times P_{t}=\int_{\Delta_{t}} L_{j, t} d j
$$

or

$$
P I_{t}=\frac{\kappa\left(1-\kappa^{\alpha}\right)}{r+\delta} I_{t}+P I_{t} \times\left(\frac{\delta}{r+\delta}+\frac{\rho r \kappa^{\alpha+1}}{r+\delta}\right)
$$

Proposition 1 is then obtained by solving for $P$ as a function of $\kappa$ in (2.10) and plugging the expression in (2.8). That $(2.1)$ has a unique solution over $[0,1]$ is easy to see with a monotonicity argument.

Equation (2.2) shows that banks discount promised repayments $\kappa I_{t}$ at a rate $r+s$, where the equilibrium spread $s$ is equal to $\frac{r}{\alpha}$. The spread increases with respect to $r$ and $\sigma$ and decreases with respect to $\delta$ but does not depend on eviction costs. The eviction costs $\lambda$ have an adverse impact on the loan-to-income ratio through $\kappa$. The spread associated with a given out-of-equilibrium $\kappa$ is $\frac{r \kappa^{\alpha}(1-\rho \kappa)}{1-\kappa^{\alpha}}$. It increases with respect to $\kappa$ because default risk is increasing in $\kappa$. This increasing spread implies that the loan supply as a function of $\kappa$ has an inverted-U shape, and is maximal for the equilibrium value of $\kappa$. The rising probability of default more than offsets the increase in promised repayments when $\kappa$ increases beyond this equilibrium value. This is reminiscent of the model of credit rationing developed by Williamson (1987). 
Assuming away eviction costs is instructive. From expressions (2.1) and (2.2), $\rho$ tends to 1 when $\lambda \rightarrow 0$, so that

$$
\begin{aligned}
\lim _{\lambda \rightarrow 0} \kappa & =1, \\
\lim _{\lambda \rightarrow 0} P_{t} & =\frac{\alpha}{\alpha+1} \times \frac{I_{t}}{r} .
\end{aligned}
$$

Thus, when foreclosures come at no cost, the repayment ratio tends to 1 , but the equilibrium home price is still strictly smaller than it would be in the benchmark model without contracting frictions. Absent such frictions, households would pledge all their income and the price $P_{t}$ would be equal to $\frac{I_{t}}{r}$. Instead, in this extreme case $\phi=1$, in which households do not have the possibility to move along the property ladder, trades in the housing market are either exogenous moving decisions or foreclosures. Because of the latter source of trades, the supply of vacant homes is large when demand is low. Negative realizations of systematic risk imply a large number of defaults and a small borrowing capacity for potential buyers. In other words, the price $P_{t}$ reflects that trading volume is negatively correlated with aggregate income because of contracts' enforcement. ${ }^{6}$ Of course, this effect becomes marginal as $\delta \rightarrow+\infty$, in which case $\alpha \rightarrow+\infty$. In this case most trades are for exogenous reasons, and supply and demand in the home market become therefore independent in the limit. Thus, the expected price of a given home, conditional on the home being sold, tends to the unconditional future market value of the home.

It is worthwhile noticing that the fact that banks do not internalize the impact of their choice of a repayment ratio $\kappa$ on the value of collateral does not reduce their supply of funds. In other words, a social planner internalizing the impact of $\kappa$ on home prices through $P$ cannot impose a value of $\kappa$ for which banks would offer a higher debt capacity than the competitive one that we obtain. ${ }^{7}$ This is because our economy is always allocationally efficient: households with linear preferences collectively occupy the fixed supply of homes, and banks make no profits. This contrasts with models that mix financing constraints and in-

\footnotetext{
${ }^{6}$ That trading volumes goes up when home prices go down is counterfactual. This is because our environment abstracts from downpayment constraints. If for example households could voluntarily move at an ET date only if they have built-up a minimal amount of home equity at this date, then more positive income realizations would entail a larger trading volume.

${ }^{7}$ To see this, note that solving for $P$ as a function of $\kappa$ in $(2.10)$, plugging the expression in $(2.7)$, and then maximizing over $\kappa$ yields the same loan-to-income ratios and home prices as in the competitive case in which banks maximize over $\kappa$ taking $P$ constant.
} 
vestment decisions, such as Bernanke and Gertler (1989), or Kiyotaki and Moore (1997). In these models, systematic risk lowers debt capacities because lenders fail to internalize the negative balance-sheet externalities that they create for each other. This leads to suboptimal investment and possibly multiple equilibria. In our setup, systematic risk affects prices through contracting frictions without distorting allocations. Endogenizing the quantity of homes could lead to financial amplification in our setup as well.

\subsection{Fully Diversifiable Income Risk}

This section studies the polar case $\phi=0$ in which there is no aggregate income risk. We solve for an equilibrium in which the unit home price $P$ is constant, and the supply of vacant homes and the income of households in the market between $t$ and $t+d t$ are $S d t$ and $I d t$ respectively, where $I$ and $S$ are constant. Note that it must be that

$$
S=I .
$$

If this equality was not satisfied, then each household would get a quantity of homes $q_{j}$ different from its income $i_{j}$ when on the market:

$$
q_{j}=\frac{i_{j}}{I} S \neq i_{j}
$$

which would imply that the total measure of homes would be different from aggregate income since all agents have been at least once in the market in the steady state. We have the following result.

Proposition 2 If banks quote a repayment ratio $\kappa \in(0,1)$ then the home price is

$$
P=\frac{\kappa}{r} \times\left[1-\frac{(1-\rho) \kappa^{\alpha}\left(1-\chi^{2 \alpha+1}\right)}{1-(\chi \kappa)^{2 \alpha+1}-\chi^{\alpha+1}\left(1-\kappa^{2 \alpha+1}\right)-\rho \kappa^{\alpha}\left(1-\chi^{2 \alpha+1}\right)}\right],
$$

where

$$
\chi=\frac{1}{1+c}, \alpha=-\frac{1}{2}+\sqrt{\frac{2(r+\delta)}{\sigma^{2}}+\frac{1}{4}}, \rho=1-\lambda\left(1+\frac{\delta}{r}\right) .
$$


The equilibrium repayment ratio is characterized by

$$
\frac{d P}{d \kappa}=0
$$

Proof. From (1.1), there are three reasons why a household becomes active in the market for vacant homes: i) the occurence of an ET date, ii) default, iii) and because its current income hits $(1+c)$ times the income it had last time it was on the market. Formally, a loan taken by household $j$ at date $t$ is now terminated at the random date $t+T$, where

$$
T=\min \left(T_{\delta}, T_{\kappa}, T_{c}\right)
$$

We already defined the variables $T_{\kappa}$ and $T_{\delta}$, and $T_{c}$ is defined as:

$$
T_{c}=\min \left\{\tau: W_{t+\tau}-W_{t}=\frac{\ln (1+c)}{\sigma}+\frac{\sigma \tau}{2}\right\}
$$

Assuming a given equilibrium repayment ratio $\kappa$, clearing the market for vacant homes yields:

$$
P S=\frac{\kappa I}{r}\left(1-E e^{-r T}\right)+P S \times E\left[e^{-r T}\left(1-\lambda \mathbf{1}_{\left\{T_{\kappa}<T_{c}, T_{\kappa}<T_{\delta}\right\}}\right)\right] .
$$

That $S=I$ implies that the equilibrium price is

$$
P=\frac{\kappa}{r} \times \frac{1-E e^{-r T}}{1-E e^{-r T}-\lambda E\left(e^{-r T_{\kappa}} \mathbf{1}_{\left\{T_{\kappa}<T_{c}, T_{\kappa}<T_{\delta}\right\}}\right)}
$$

The computations of $E e^{-r T}$ and $E\left(e^{-r T_{\kappa}} \mathbf{1}_{\left\{T_{\kappa}<T_{c}, T_{\kappa}<T_{\delta}\right\}}\right)$ that lead to expression (2.11) are relegated to the appendix in Section 6.2. Finally, that the competitive repayment ratio is the one that maximizes $P$ stems from the same reasons of allocative efficiency as in the case with systematic risk

Notice that, unlike when $\phi=1$, debt capacities tend to the first-best $\frac{I_{j, t}}{r}$ when eviction costs become small $(\lambda \rightarrow 0$ so that $\rho \rightarrow 1)$. Yet, as we show now, debt capacities are not necessarily higher when $\phi=0$ in general. 


\subsubsection{Comparing the cases $\phi=0$ and $\phi=1$}

It is interesting to first compare loan-to-income ratios for $\phi=0$ and $\phi=1$ when switching costs $c$ become large. In this case, contracts are terminated for two reasons only - ET dates or default - for both values of $\phi$. As $c \rightarrow+\infty$, the limiting value of $(2.11)$ is

$$
\lim _{c \rightarrow+\infty} P=\frac{\kappa}{r} \times \frac{1-\kappa^{\alpha}}{1-\rho \kappa^{\alpha}}
$$

and the optimal repayment ratio - the one that maximizes $P$ - is the root within $(0,1)$ of:

$$
\rho \alpha \kappa^{2 \alpha}-(1+\alpha) \kappa^{\alpha}+1=0 .
$$

From (2.2), the loan-to-income ratio for a given repayment ratio $\kappa$ if income risk is fully systematic is $\frac{\kappa\left(1-\kappa^{\alpha}\right)}{1-\rho \kappa^{\alpha+1}}$. Comparing with (2.13) yields the following result:

Proposition 3 Equilibrium loan-to-income ratios and initial home prices are larger when income risk is diversifiable if and only if

$$
\rho \geq 0 \Longleftrightarrow \lambda \leq \frac{r}{r+\delta}
$$

Proof. Let $\kappa_{S}$ and $\kappa_{I}$ denote the respective equilibrium repayment ratios when $\phi=1$ and $\phi=0$ respectively. If $\rho \geq 0$, then

$$
\frac{\kappa_{I}\left(1-\kappa_{I}^{\alpha}\right)}{1-\rho \kappa_{I}^{\alpha}} \geq \frac{\kappa_{S}\left(1-\kappa_{S}^{\alpha}\right)}{1-\rho \kappa_{S}^{\alpha}} \geq \frac{\kappa_{S}\left(1-\kappa_{S}^{\alpha}\right)}{1-\rho \kappa_{S}^{\alpha+1}}
$$

If $\rho \leq 0$, then

$$
\frac{\kappa_{S}\left(1-\kappa_{S}^{\alpha}\right)}{1-\rho \kappa_{S}^{\alpha+1}} \geq \frac{\kappa_{I}\left(1-\kappa_{I}^{\alpha}\right)}{1-\rho \kappa_{I}^{\alpha+1}} \geq \frac{\kappa_{I}\left(1-\kappa_{I}^{\alpha}\right)}{1-\rho \kappa_{I}^{\alpha}}
$$

The intuition for this result is the following. The expected proceeds from a loan are the sum of three components: i) the promised repayments until default or an exogenous move, (ii) sale proceeds net of eviction costs in case of default, (iii) proceeds from selling the vacant home if the household moves for exogenous reasons. Whether income risk is diversifiable or not has no impact on the value of component (i). That income risk is idiosyncratic implies that the income of a given household is uncorrelated with home market values at default 
and ET dates. This is good news for component (ii), which represents situations in which individual income has done poorly, but bad news for (iii) in which individual income has done rather well. As $\delta$ and $\lambda$ increase, a larger fraction of total loan value stems from component (iii) rather than component (ii). Thus, diversification has an adverse impact in this case. In sum, diversifiability of income risk implies that the home price that a bank receives upon termination of a given mortgage is not tied to the income of the borrower at the date of termination. This is beneficial to the bank when the borrower is unable to repay and is evicted because its income is low. This is detrimental to the bank when the borrower voluntarily exits the contract and its income is high.

Consistent with the one-sided commitment assumed here, households just vacate their current home when they seek to move. Thus, the bank's expected prepayment is the home market value, and this drives the negative impact of diversification shown in Proposition 3. In practice, households have more commitment power. Upon moving, they typically sell their house to prepay their mortgage according to pre-agreed terms. We believe that this departure from our model cannot fundamentally reduce the negative impact of diversification that we established. Banks can still not fully capture idiosyncratic income appreciation through high pre-agreed repayments. High repayments that exceed home values would create high incentives for strategic default, particularly so for non-recourse loans.

In the presence of a finite switching $\operatorname{cost} c$, it is no longer clear that equilibrium loanto-income ratios are larger with $\phi=0$ than with $\phi=1$, even for values of $\delta$ and $\lambda$ that satisfy (2.14). In this case, the costs of diversification are more important because the crosssectional mobility of incomes implies that good borrowers exercise their option to climb up the property ladder more often. Table 1 reports the values of $c$ below which equilibrium debt capacity is lower when income risk is diversifiable than when it is systematic for different values of $\delta$. 


\begin{tabular}{|c|c|}
\hline $1+c$ & $\delta$ \\
\hline 1.03 & 0.02 \\
\hline 1.14 & 0.03 \\
\hline 1.20 & 0.04 \\
\hline 1.32 & 0.05 \\
\hline 1.40 & 0.06 \\
\hline 1.47 & 0.07 \\
\hline 1.55 & 0.08 \\
\hline 1.61 & 0.09 \\
\hline 1.69 & 0.1 \\
\hline
\end{tabular}

Table 1. Values of $c$ below which systematic risk is preferable for various values of $\delta$, with

$$
r=2 \%, \sigma=20 \%, \lambda=15 \% \text {. }
$$

The values of $c$ below which diversifiable income risk yields lower debt capacities become quickly very high as $\delta$ increases. Thus the costs of diversification become quickly as important as the benefits from higher collateral values. In sum, our setup of long-term contracting with one-sided commitment and informational asymmetry exhibits a trade-off between two effects of ex post heterogeneity. These effects have been studied independently so far. We show that the flip side of the gains from higher equilibrium liquidation values is a higher cost of the lack of borrowers' commitment.

\subsubsection{Turnover in the Steady-State}

With fully diversifiable income, we can simply characterize several other features of the economy. Unlike representative-agent models, our model explicitly predicts trading intensities motivated by default, renegotiation, or ET. This implies in turn that we can compute the supply of vacant homes $S$, and the income of households in the market $I$ between $t$ and $t+d t$. We have the following results.

\section{Proposition 4}

We have

$$
S=I=\frac{1-p_{\kappa}-p_{c}}{1-\kappa p_{\kappa}-\frac{p_{c}}{\chi}},
$$


where

$$
\begin{aligned}
p_{c} & =\operatorname{Prob}\left(T_{c}<T_{\kappa} ; T_{c}<T_{\delta}\right)=\frac{\kappa^{-\omega}-\kappa^{\omega}}{\left((\kappa \chi)^{-\omega}-(\kappa \chi)^{\omega}\right) \sqrt{\chi}} \\
p_{\kappa} & =\operatorname{Prob}\left(T_{\kappa}<T_{c} ; T_{\kappa}<T_{\delta}\right)=\frac{\left(\chi^{-\omega}-\chi^{\omega}\right) \sqrt{\kappa}}{(\kappa \chi)^{-\omega}-(\kappa \chi)^{\omega}} \\
\omega & =\sqrt{\frac{2 \delta}{\sigma^{2}}+\frac{1}{4}}
\end{aligned}
$$

The steady-state arrival intensity of households in the market is $\frac{\delta}{1-p_{\kappa}-p_{c}}$. The respective arrival intensities of households who default, renegotiate, and exogenously terminate the contract are $\frac{\delta p_{\kappa}}{1-p_{\kappa}-p_{c}}, \frac{\delta p_{c}}{1-p_{\kappa}-p_{c}}$, and $\delta$ respectively.

Proof. The proofs of (2.15) and (2.16) are in Section 6.2 of the appendix. We compute $I$ and $S$. Consider a household which is in the market at date $t$. The next time this household will be in the market will be when the first of the three following events occur: ET date, default, or renegotiation. By definition $p_{\kappa}$ and $p_{c}$ are the respective probabilities that the first of these events are default and renegotiation respectively. The income of a household which is in the market is reset to 1 if it is in the market because of an exogenous termination. If not, its income can be characterized with the two integers $m$ and $n$ - such that $m+n>0$ - that count the respective numbers of times the household has defaulted and renegotiated since the last time its income was reset to 1 . Its income is then equal to

$$
\kappa^{m}(1+c)^{n} .
$$

Thus we have

$$
S=I=\left(1-p_{\kappa}-p_{c}\right)+\sum_{\substack{m, n \\
m+n>0}}\left(\begin{array}{c}
m \\
m+n
\end{array}\right)\left(1-p_{\kappa}-p_{c}\right)\left(p_{\kappa} \kappa\right)^{m}\left(p_{c}(1+c)\right)^{n}=\frac{1-p_{\kappa}-p_{c}}{1-\kappa p_{\kappa}-(1+c) p_{c}} .
$$

Furthermore, a steady-state fraction $1-p_{\kappa}-p_{c}$ of the households who are in the market are in the market because of the realization an ET date. Since such dates occur with intensity $\delta$, the total steady-state arrival intensity of households in the market is $\frac{\delta}{1-p_{\kappa}-p_{c}}$, and the respective arrival intensities of households who default and renegotiate are $\frac{\delta p_{\kappa}}{1-p_{\kappa}-p_{c}}$ and $\frac{\delta p_{c}}{1-p_{\kappa}-p_{c}}$ respectively. 
This full characterization of trading patterns in mortgage and housing markets offers insights on the equilibrium consequences of a decrease in $c$ due to regulatory, technological, or competitive changes. As we will see shortly, a decrease in $c$ implies lower debt capacities and lower repayment ratios $\kappa$, but yet more aggregate lending per unit of time because more households are in the market at each date. It also implies a higher equilibrium default intensity because more households are close to their default boundary in the steady-state. It is interesting to relate this effect to some patterns of the recent U.S. housing boom and subsequent subprime crisis. It is widely believed ${ }^{8}$ that a heavy reliance on frequent refinancing was an important characteristic of subprime mortgages, which were designed to create a strong incentive for households to refinance. As a result, and as predicted by our model, as the total debt capacity of subprime borrowers increased, so did aggregate defaults. The change in defaults, however, occurred only with a lag since it takes time for households to hit the default boundary of a freshly refinanced mortgage. Failure to have correctly anticipated this equilibrium change may contribute to explain the observed mis-pricing of many subprimebacked securities.

\subsubsection{Orders of magnitude}

Our model with fully idiosyncratic income risk gives plausible broad orders of magnitude. Assume a (real) rate of $2 \%$, a volatility of households' income of $20 \%$ (see Dynan et al., 2008), ET dates that arrive with an intensity of $5 \%$ - corresponding to a contractual mortgage duration of 20 years, and a relocation threshold $1+c$ of 1.5 . This yields an equilibrium loan equal to $35 \%$ of expected perpetual income $\frac{I_{j, t}}{r}$. This corresponds to an optimal repayment ratio $\kappa$ of $50 \%$, an arrival intensity in the market $\frac{\delta}{1-p_{\kappa}-p_{c}}$ of $15 \%$ corresponding to an effective contractual relationship of 6.5 years, and a default intensity of $2.3 \%$. Note that our model is too abstract to distinguish between mortgages and leases, so that the appropriate empirical counterparts of these numbers should take into account the rental market. Fabozzi (2006) reports average front-end debt-to-income ratios of $40 \%$ for subprime borrowers, and back-end ratios averaging above $50 \% .{ }^{9}$ Considering our focus on subprime borrowers, and the fact that we do not explicitly model a fixed subsistence level of consumption, a 50\% loan-to-income

\footnotetext{
${ }^{8}$ See, for example, Gorton (2008).

${ }^{9}$ The front-end ratio divides mortgage payments, real estate taxes, and home insurance premia by gross income. The back-end ratio adds other obligations such as credit card and automobile debt to the numerator.
} 
ratio is a reasonable first pass. The trading intensity of $15 \%$ seems also reasonable given that sales of existing units plus changes in unsold inventories account for $5-8 \%$ of the total stock of U.S. housing units, but that the turnover is typically higher in the rental market. ${ }^{10}$ Finally, the default intensity of $2.3 \%$ is in line with the rate of mortgage delinquencies for borrowers with low FICO scores observed by Keys et al. (2006) in 2006, and slightly above the rates that they observe between 2002 and 2005.

Figure 1 shows the evolution of the loan-to-income ratio as a function of $\delta$ and $\chi=\frac{1}{1+c}$.

[Figure 1 About Here]

Debt capacity is not too sensitive to $\delta$ for low values of $\chi$. Conversely, as the cost at which households climb the property ladder decreases ( $\chi$ close to 1$)$, the commitment problem becomes quickly very costly and hurts debt capacity. Interestingly, unlike in the fully systematic case, an increase in the ET intensity $\delta$ actually reduces debt capacity provided $\delta$ and $\chi$ are small. We provide an intuition for this result in the next section. The high impact of $\chi$ on debt capacity stems from the fact that renegotiation intensity soars as $c$ becomes smaller than $30 \%$.

Figure 2 shows the equilibrium value of the steady-state default intensity $\frac{\delta p_{\kappa}}{1-p_{\kappa}-p_{c}}$.

[Figure 2 About Here]

Interestingly, equilibrium defaults increase w.r.t. $\chi$ and $\delta$ when $\delta$ is small. It is so despite the fact that the repayment ratio $\kappa$ decreases w.r.t. $\chi$ and $\delta$ for such small values of $\delta$. The intuition is the following. If $\delta$ is large, the dominant effect of an increase in $\delta$ is that it "completes contracts", and reduces the needs for enforcement through evictions. When all else equal $\delta$ is small, the dominant effect of an increase in $\chi$ or $\delta$ is a negative equilibrium effect on the distribution of households' solvency. As $\delta$ increases, since households enter new contracts and thus maximize their debt capacity more often, there is a higher fraction of households closer to their default boundary in the steady-state. Otherwise stated, the dominant effect in this case is that an increase of $\delta$ or $\chi$ reduces the steady-state fraction of

\footnotetext{
${ }^{10}$ Deng et al. (2003) report high tenant turnover rates at about 3 years of residence.
} 
households that are very safe borrowers. To see this, Figure 3 illustrates how the steady-state density of

$$
\frac{I_{j, t+s}-\kappa I_{j, t}}{I_{j, t}-\kappa I_{j, t}}
$$

where $t$ is the date at which the loan was originated, varies as a function of $\delta$ for $\chi=0 .{ }^{11}$

\section{[Figure 3 About Here]}

Figure 3 shows the density for values of (2.17) ranging from 0 (default) to $25 \%$. This confirms that the dominant impact of an increase in $\delta$ for $\delta$ and $\chi$ small is an increase in the number of risky borrowers.

Figure 4 illustrates the income of households in the market $I$. Recall that the unconditional expected income is 1.

[Figure 4 About Here]

The income of households in the market reflects the weights of each motive to trade. For small $\chi$ and $\delta$, lots of trades follow from foreclosures and thus there is a large majority of households whose income has done poorly in the market. Conversely, $I$ becomes nearly $20 \%$ higher than unconditional income as the fraction of households which trade to climb up the property ladder rises. Finally, Figure 5 shows that the total loans granted between $t$ and $t+d t$, equal to $P \times I$, increase with $\delta$ and $\chi$.

[Figure 5 About Here]

\subsubsection{Contractible Prices}

As already mentioned, the assumption that prices are not contractible seems more realistic. Under the alternative assumption that contracts can be indexed on prices and thus on aggregate income, the general case in which $\phi \in(0,1)$ is a straightforward application of the case in which income is fully diversifiable. The only difference is that repayments and prices are multiplied by the systematic component of income.

\footnotetext{
${ }^{11}$ The derivation of a closed-form expression for this steady-state density is available upon request.
} 


\subsection{General Income Risk}

The general case in which $\phi \in(0,1)$ and prices are not contractible is not analytically tractable because, unlike when $\phi \in\{0,1\}$, demand and supply of vacant homes depend in complex and different fashions on the history of aggregate income risk. Essentially, the distribution of idiosyncratic incomes of households who are in the market is no longer stationary as it was in the two polar cases that we studied. In particular the key property $S=I$ that holds when $\phi \in\{0,1\}$ no longer does. It is possible, however, to solve for prices and loan-to-income ratios in a modified version of the model in which the distribution of income is improper. Formally, we modify our baseline model as follows:

Assumption 1. Idiosyncratic income is not re-set at ET dates. Thus, the income process of household $j \in[0,1]$ is simply

$$
I_{j, t}=I_{t} \times i_{j, t}, \quad \frac{d I_{t}}{I_{t}}=\phi \sigma d W_{t}, \quad \frac{d i_{j, t}}{i_{j, t}}=\sqrt{1-\phi^{2}} \sigma d W_{j, t}
$$

and again all processes are pairwise independent.

Assumption 2. Idiosyncratic log-incomes $\left(\ln i_{j, 0}\right)_{j \in[0,1]}$ have an improper uniform distribution over the real line. Also, $i_{j, 0}=q_{j, 0}$ for all $j \in[0,1]$.

We assume away renegotiation $(c=+\infty)$.

This setup clearly has the unpalatable property that aggregate supply and demand do not exist absent a proper income distribution. However, there still exists a unit price of the form $P_{t}=P I_{t}$ and a loan-to-income ratio such that banks maximize expected proceeds per loan and each household solves (1.1). When interpreting the results, one has to keep in mind, however, that changes in the parameters would have additional complex effects in a model with a proper income distribution, unless this distribution is extremely diffuse. We have the following result:

\section{Proposition 5}

Let

$$
\beta=\sqrt{\frac{2(r+\delta)}{\sigma^{2}}+\frac{1}{4}-\phi^{2}\left(1-\phi^{2}\right)}-\frac{1}{2}+\phi^{2}
$$

There is a unique $(\kappa, P) \in(0,1) \times(0,+\infty)$ such that if banks believe that home prices are $P_{t}=P I_{t}$, then banks maximize expected proceeds by quoting a repayment ratio $\kappa$, households 
solve (1.1), and beliefs are correct.

Banks quote the repayment ratio $\kappa$ which solves:

$$
(\alpha+1) \kappa^{\alpha}=1-\rho \kappa^{\beta}\left(1-\beta-(1+\alpha-\beta) \kappa^{\alpha}\right),
$$

and the price of a home is:

$$
P_{t}=P I_{t}=\frac{1-\kappa^{\alpha}}{1-\rho \kappa^{\beta}} \times \frac{\kappa}{r} I_{t}
$$

Proof. Assume that banks believe that home prices satisfy

$$
\forall u \geq 0, P_{t+u}=P I_{t+u}
$$

for some constant $P>0$. Again, a loan taken by household $j$ at date $t$ with contractual repayment $\kappa I_{j, t}$ is terminated at the random date $t+T^{j, t}$, where

$$
T^{j, t}=\min \left(T_{\delta}^{j, t}, T_{\kappa}^{j, t}\right)
$$

with:

$$
T_{\delta}^{j, t}=\min \aleph_{j} \cap(t,+\infty),
$$

and

$$
\left\{T_{\kappa}^{j, t}=\tau\right\} \Longleftrightarrow \phi\left(W_{t+\tau}-W_{t}\right)+\sqrt{1-\phi^{2}}\left(W_{j, t+\tau}-W_{j, t}\right)=\frac{\ln (\kappa)}{\sigma}+\frac{\sigma \tau}{2} .
$$

Let $\Delta_{t}$ denote the subset of households who switch homes between $t$ and $t+d t$. If a bank quotes an equilibrium repayment ratio $\kappa$ and unit loan $L$ then the expected repayments from household $j \in \Delta t$ are

$$
L \times I_{j, t}=E_{t}\left(\begin{array}{c}
\int_{t}^{t+T^{j, t}} e^{-r s} \kappa I_{j, t} d s+(1-\lambda) e^{-r T^{j, t}} 1_{\left\{T_{\delta}^{j, t}>T_{\kappa}^{j, t}\right\}} P_{t+T_{\kappa}^{j, t}} q_{j, t} \\
+1_{\left\{T_{\delta}^{j, t} \leq T_{\kappa}^{j, t}\right\}} e^{-r T^{j, t}} P_{t+T_{\delta}^{j, t}} q_{j, t}
\end{array}\right)
$$

where $\left(q_{j, t}\right)_{j \in \Delta_{t}}$ are the quantities of homes bought by $j \in \Delta_{t}$. An equilibrium home price 
$P I_{t}$ satisfies $P I_{t}=\frac{L I_{j, t}}{q_{j, t}}$ for all $j \in \Delta_{t}$. Thus,

$\int_{\Delta_{t}} d j \times P I_{t}=\int_{\Delta_{t}} \frac{L I_{j, t}}{q_{j, t}} d j=\int_{\Delta_{t}} E_{t}\left(\begin{array}{c}\frac{i_{j, t}}{q_{j, t}} \times \int_{t}^{t+T^{j, t}} e^{-r s} \kappa I_{t} d s+(1-\lambda) e^{-r T^{j, t}} 1_{\left\{T_{\delta}^{j, t}>T_{\kappa}^{j, t}\right\}} P I_{t+T_{\kappa}^{j, t}} \\ +1_{\left\{T_{\delta}^{j, t} \leq T_{\kappa}^{j, t}\right\}} e^{-r T^{j, t}} P I_{t+T_{\delta}^{j, t}}\end{array}\right) d j$.

In the baseline model with proper income distributions, $\int_{\Delta_{t}} d j$ and $\int_{\Delta_{t}} \frac{i_{j, t}}{q_{j, t}} d j$ are difficult to characterize because past realizations of aggregate income risk drive the current home supply and the distribution of income in the market in different fashions, except when $\phi \in\{0,1\}$. Under the simplifying assumption of an improper distribution, the cross-sectional distribution of log idiosyncratic incomes in the market is constantly uniform, so that $i_{j, t}=q_{j, t}$ for all $j, t$, and

$$
P I_{t}=\begin{gathered}
\kappa I_{t} \times E\left(\int_{0}^{T} e^{-r s} d s\right)+(1-\lambda) P \times E\left(e^{-r T} 1_{\left\{T_{\delta}>T_{\kappa}\right\}} I_{t+T}\right) \\
+P \times E\left(e^{-r T} 1_{\left\{T_{\delta} \leq T_{\kappa}\right\}} I_{t+T}\right) .
\end{gathered}
$$

Applying Lemma 1 with $\nu=0$ to compute the right-hand-side of (2.18) yields the proposition.

Note that the loan-to-income ratio obtained in Proposition 5 tends to the values of the baseline model when $\phi$ tends to 0 or 1 . This is because the improper distribution buys us a property of stationary distribution of idiosyncratic incomes in the market that holds in the baseline model only for $\phi=0$ and $\phi=1$. Note also in passing that the loan-to-income ratio depends on $\phi$ only through $\beta$. Since the denominator of the loan-to-income ratio is $1-\rho \kappa^{\beta}$, the sign of $\rho$ drives the impact of diversification as already seen in Proposition 3.

Figure 6 shows the respective impact of $\phi$ and $\delta$ on loan size.

[Figure 6 About Here]

Perhaps most surprising is the impact of $\delta$ on loan size. First, for all values of $\phi$, the loan size tends to the first best $\frac{I_{j, t}}{r}$ as $\delta \rightarrow+\infty$. This is because arbitrarily frequent ET dates "complete contracts" by ensuring that repayments are re-set very often at current income levels. Note that convergence is quite slow, however, because discrete re-settings of contracts closely track the diffusive part of income only when done at very high frequencies. Second, the equilibrium loan size decreases (increases) with respect to $\delta$ for small values of $\delta$ when $\phi$ 
is small (large). The intuition for this result is related to the one behind Proposition 3. An increase in $\delta$ has two positive effects and one negative effect:

1. The first positive effect is a reduction in expected eviction costs.

2. The second positive effect is that it increases the fraction of home sales that do not occur when the common component of incomes is low.

3. The negative effect is that a home is sold for exogenous reasons only if the household has not defaulted before the ET date. This implies that the conditional distribution of its income at an ET date is skewed to the right. Conditional skewness becomes more significant as $\delta$ decreases. This conditional skewness implies that sales on ET dates occur when outstanding loans are highly valuable to the bank.

The second positive effect plays an important role only in the presence of systematic risk. Conversely, the third negative effect is more important absent systematic risk because in this case the resale price of a home has no reason to be particularly high when the idiosyncratic income of the household is high. Thus trading a very safe loan for the market price of vacant home at an ET date is a bad deal. This is why the effect of an increase in $\delta$ can be negative when most income risk is idiosyncratic and $\delta$ is low.

\section{Nonlinear Prices}

This section studies equilibria in which the price is not a linear function of aggregate income. To fix ideas and ease the exposition, we study the simplest model of Section 2.1 in which all income risk is systematic $(\phi=1)$. Results similar to the ones that we establish in this case hold in the other cases studied in Section 2. Consider the benchmark of a frictionless economy in which households' income is fully pledgeable. Such a model is equivalent to an infinitehorizon economy in which risk-neutral agents price a claim to a consumption flow $\left(I_{t}\right)_{t \geq 0}$.

In this case, the price $P_{t}=\frac{I_{t}}{r}$ is the only equilibrium price that satisfies a transversality condition

$$
\lim _{s \rightarrow+\infty} E_{t}\left(e^{-r s} P_{t+s}\right)=0
$$


Absent such a transversality condition, it is well-known that "bubbly" price paths satisfy the no-arbitrage condition as long as the bubble component of the price has an expected growth rate equal to $r$. We examine the counterparts of these results in our environment with contracting frictions. We first establish that the linear equilibrium price derived in Proposition 1 is the only equilibrium price that satisfies a transversality condition.

Proposition 6 The only equilibrium in which the price process satisfies (3.1) is the one described in Proposition 1.

Proof. See Section 6.3 in the Appendix.

Thus, contracting frictions do not modify the property of the unconstrained economy that the linear equilibrium is the only one without exploding price paths. We now investigate which type of bubbly equilibria can be sustained. We first look for simple deterministic bubbles of the form

$$
P_{t}=P I_{t}+B e^{b t}
$$

where $(P, B, b) \in \mathbb{R}_{+}^{3}$. We have the following result.

Proposition 7 Equilibria in which the price is of the form (3.2) are such that $B=0$.

Proof. We introduce the variable $s=r-b$ and stress the dependence of the coefficient $\alpha$ on $r$ with the notation $\alpha(r)=\sqrt{\frac{2(r+\delta)}{\sigma^{2}}+\frac{1}{4}}-\frac{1}{2}$. Let $\kappa$ denote the equilibrium repayment ratio. The market-clearing condition in the linear case (2.10) becomes with a price of the form $(3.2)$

$$
P I_{t}+B=\left[\frac{\kappa\left(1-\kappa^{\alpha(r)}\right)}{r+\delta}+P \times \frac{r \rho \kappa^{\alpha(r)+1}+\delta}{r+\delta}\right] I_{t}+B\left(\frac{s \kappa^{\alpha(s)}+\delta}{s+\delta}-\lambda \kappa^{\alpha(s)}\right)
$$

This is a straightforward consequence from Lemma 1 and equation (6.3). Note that the right-hand side of (3.3) is finite only for $b<r+\delta$. An equilibrium price with $B>0$ requires that $\kappa$ is such that

$$
\frac{s \kappa^{\alpha(s)}+\delta}{s+\delta}=1+\lambda \kappa^{\alpha(s)}
$$

and also that $\kappa$ maximizes the right-hand side of (3.3) taking all other parameters fixed. It is easy to see that such a $\kappa$ cannot exist: solutions to equation (3.4) do not depend on $I_{t}$ while 
a $\kappa$ that maximizes the right-hand side of (3.3) does.

If income was fully pledgeable, a constant bubble could grow at the rate $b=r$ absent a transversality condition. Contracting frictions prevent such bubbles to be sustainable equilibrium outcomes. In the presence of a bubble, unlike in the linear case, each bank chooses a repayment ratio that depends on current income level $I_{t}$. With such repayment ratios, the equilibrium price cannot be of the form (3.2) in this case. It is possible to show similarly that bubbles that burst with a fixed intensity à la Blanchard and Watson (1982) cannot be sustained in this environment.

That the repayment ratio chosen by banks depends on $I_{t}$ in the presence of a bubble suggests to look at a class of bubbly price paths of the form

$$
P_{t}=P I_{t}+F\left(I_{t}\right)
$$

where $P=\frac{1-\kappa^{\alpha}}{1-\rho \kappa^{\alpha+1}} \times \frac{\kappa}{r}$, and $F: \mathbb{R}_{+} \rightarrow \mathbb{R}_{+}$is differentiable. The following proposition characterizes equilibria with a price of the form (3.5).

\section{Proposition 8}

If an equilibrium features a repayment ratio $\kappa$ (depending on $I_{t}$ ) and a price of the form (3.5), then for all $I_{t}$

$$
F\left(I_{t}\right)=(1-\lambda) \kappa^{\alpha} F\left(\kappa I_{t}\right)+\frac{2 \delta}{(2 \alpha+1) \sigma^{2}}\left(\begin{array}{c}
\left(1-\kappa^{2 \alpha+1}\right) \int_{1}^{\infty} F\left(I_{t} y\right) y^{-(2+\alpha)} d y \\
+\int_{\kappa}^{1} F\left(I_{t} y\right)\left(y^{\alpha-1}-y^{-(2+\alpha)} \kappa^{2 \alpha+1}\right) d y
\end{array}\right)
$$

and

$$
\frac{1-(1+\alpha) \kappa^{\alpha}+\rho \alpha \kappa^{1+\alpha}}{\left(1-\rho \kappa^{1+\alpha}\right)^{2}} \times \frac{I_{t}}{r}+(1-\lambda) \frac{\partial}{\partial \kappa}\left(\kappa^{\alpha} F\left(\kappa I_{t}\right)\right)-\frac{2 \delta}{\sigma^{2}} \kappa^{2 \alpha} \int_{\kappa}^{\infty} F\left(I_{t} y\right) y^{-(2+\alpha)} d y=0
$$

\section{Proof. See Section 6.4 of the appendix.}

Equation (3.6) is the market-clearing condition. Equation (3.7) is the first-order condition associated with the banks' choice of an optimal $\kappa$. In an unconstrained economy with Brownian dividends similar to our income process, Froot and Obstfeld (1991) exhibit an interesting bubbly price path of the form $F\left(I_{t}\right)=C I_{t}^{\gamma}$ with $\gamma>1$. Again, such "intrinsic" bubbles do 
not correspond to equilibrium price paths in our model with contracting frictions. ${ }^{12}$

We do not know whether there exists or not a function $F(I)$ different from zero and a repayment ratio $\kappa(I)$ that solve the system of functional equations (3.6) and (3.7). Notwithstanding this open question, it is interesting to study the characteristics of such hypothetical equilibria. They display relationship between home price paths and contracting terms that are reminiscent of what has been recently observed in subprime markets. Consider the simple case in which the total value of a home is lost in the foreclosure process $(\lambda=1)$. We have

\section{Proposition 9}

Consider a positive function $F($.$) and an associated repayment ratio \kappa_{F}($.$) that satisfy$ (3.6) and (3.7) for $\lambda=1$. Then

1. If $F \neq 0$, then $\kappa_{F}(I)<\kappa_{0}$ for all $I>0$, where $\kappa_{0}$ is the (constant) equilibrium repayment ratio in the linear equilibrium. Furthermore, 0 is an accumulation point of $\kappa_{F}(I)$ as $I \rightarrow+\infty$, and $+\infty$ is an accumulation point of the loan-to-income ratio as $I \rightarrow+\infty$.

2. If $F(I)$ is increasing and $\alpha>1$, or if $\frac{F(I)}{I}$ is increasing, then $\kappa_{F}($.$) decreases from \kappa_{0}$ to 0 as $I_{t}$ increases from 0 to $+\infty$.

Proof. 1. Assume $\lambda=1$ and let

$$
\Phi(I)=\frac{F(I)}{I}
$$

for a candidate solution $F$. Equation (3.7) is then

$$
\frac{1-(1+\alpha) \kappa_{F}\left(I_{t}\right)^{\alpha}-\frac{\delta \alpha \kappa_{F}\left(I_{t}\right)^{1+\alpha}}{r}}{\left(1+\frac{\delta \kappa_{F}\left(I_{t}\right)^{1+\alpha}}{r}\right)^{2}}=\frac{2 \delta r}{\sigma^{2}} \kappa_{F}\left(I_{t}\right)^{2 \alpha} \int_{\kappa_{F}\left(I_{t}\right)}^{\infty} \Phi\left(I_{t} y\right) y^{-(1+\alpha)} d y
$$

The left-hand side of (3.8) is the derivative with respect to $\kappa$ of the loan-to-income ratio $\frac{\kappa\left(1-\kappa^{\alpha}\right)}{1-\rho \kappa^{\alpha+1}}$ that would prevail were the equilibrium linear. The numerator is a decreasing function with one zero. Thus, in the presence of a bubble, it must be that the repayments are smaller than the ones that are optimal with a linear price in order to satisfy (3.8). If $F \neq 0$,

\footnotetext{
${ }^{12}$ To see this, note that with $F\left(I_{t}\right)=C I_{t}^{\gamma}$, equation (3.6) implies that an equilibrium $\kappa$ should be a constant, while it is easy to see from (3.7) that $\kappa$ must depend nontrivially on $I_{t}^{\gamma-1}$.
} 
then $\Phi(I)$ cannot be bounded. Otherwise it would imply that the price satisfies the transversality condition. From (3.8), this implies that 0 must be an accumulation point of $\kappa_{F}($.$) in$ $+\infty$. Also, the loan-to-income ratio $\frac{\kappa\left(I_{t}\right)\left(1-\kappa\left(I_{t}\right)^{\alpha}\right)}{1+\frac{\delta \kappa\left(I_{t}\right)^{\alpha+1}}{r}}+r \Phi\left(I_{t}\right)$ is unbounded.

2. To establish that if $F($.$) is increasing and \alpha>1$, then the repayment ratio $\kappa_{F}\left(I_{t}\right)$ is decreasing from $\kappa_{0}$ to 0 when $I_{t}$ goes from zero to infinity, it suffices to notice that the right-hand side of (3.8) increases w.r.t. $\kappa_{F}\left(I_{t}\right)$ for $F(\cdot)$ increasing and $\alpha>1$. To see this, note that

$$
\begin{aligned}
\frac{\partial}{\partial \kappa}\left(\kappa^{2 \alpha} \int_{\kappa}^{\infty} \Phi\left(I_{t} y\right) y^{-(1+\alpha)} d y\right) & =\kappa^{\alpha-1}\left(2 \alpha \kappa^{\alpha-1} \int_{\kappa}^{\infty} \frac{F\left(I_{t} y\right)}{I_{t}} y^{-(2+\alpha)} d y-\phi\left(I_{t} \kappa\right)\right) \\
& \geq \kappa^{\alpha-1}\left(\frac{2 \alpha}{1+\alpha} \kappa^{-\alpha} \phi\left(I_{t} \kappa\right)-\phi\left(I_{t} \kappa\right)\right) \geq 0 .
\end{aligned}
$$

That this result also holds when $\Phi(\cdot)$ is increasing is established similarly

Thus, the self-justified belief that the price path is explosive implies that banks set lower repayment ratios despite quoting larger loan-to-income ratios. The intuition is that defaults become quite costly in the presence of a bubble because they limit banks' ability to ride it. Future home value is a more important component of the loan than the current borrower's ability to repay. Time-variations in repayment ratios should also amplify the sensitivity of default intensities to income paths in the bubbly case (if such a case exists) compared with the linear equilibrium. After a negative shock on $I_{t}$, not only do some borrowers default on their current loans, but newly issued loans also feature higher repayment ratios and thus lower distances to default. This will generate more future defaults after a lag. The impact of income shocks on default intensities is therefore more persistent with bubbly equilibria than in the linear one.

Nonlinear dynamics are generated by the procyclicality of loan-to-income ratios that become very large when income is high. Almeida et al. (2006) and Lamont and Stein (1999) find evidence of such an amplification through procyclical leverage in housing markets.

\section{Towards Optimal Contracts}

We restricted the analysis to contracts with constant repayments for tractability. This section studies the impact of this restriction by allowing for repayment schedules that depend on time 
elapsed since the origination of the loan. The goal is to show that equilibrium quantities in this richer contracting environment do not differ significantly from the ones derived thus far. We focus on the case in which income risk is diversifiable $(\phi=0)$ and all trades correspond to exogenous terminations or foreclosures $(c=+\infty)$ for expositional simplicity. The optimal repayment schedule is a number $\kappa$ and a function of the time elapsed since origination $g(\cdot)$ such that if the contract has been originated at date $t$, then the $t+s$ contractual repayment is $\kappa e^{-g(s)}$. We have the following characterization of the optimal contract.

\section{Proposition 10 Let}

$$
T_{g}^{t}=\min \left\{\tau \geq 0: W_{j, t+\tau}-W_{j, t}=\frac{\ln (\kappa)-g(\tau)}{\sigma}+\frac{\sigma \tau}{2}\right\}
$$

and

$$
Q_{g}(\tau)=\operatorname{Prob}\left(T_{g}^{t} \geq t+\tau\right)
$$

the optimal contract $\kappa, g(\cdot)$ solves

$$
\max _{\kappa \in[0,1], g(\cdot)} \frac{\kappa \int_{0}^{\infty} Q_{g}(s) e^{-g(s)-(r+\delta) s} d s}{\lambda+\rho r \int_{0}^{\infty} Q_{g}(s) e^{-(r+\delta) s} d s} .
$$

Proof. See Section 6.5 in the appendix.

The problem does not seem to be analytically solvable. A possible numerical solution consists in optimizing over piecewise linear functions $g(t)$, corresponding to piecewise linear log-repayments. We go along this route by studying simple repayments that are log-linear and log-linear with one kink. We first solve for the equilibrium price with loglinear contracts.

Proposition 11 Assume that at date $t$, banks quote loans such that household $j \in[0,1]$ promises to repay $\kappa I_{j, t} e^{-\sigma^{2} \nu \tau}$ at each future date $t+\tau$, with $(\kappa, \nu) \in(0,1) \times \mathbb{R}$. The price of a home and the loan to-income-ratio are equal to

$$
P=\frac{r+\delta}{r+\delta+\sigma^{2} \nu} \times \frac{\kappa\left(1-\kappa^{\alpha_{\nu}}\right)}{r\left(1-\rho \kappa^{\alpha_{\nu}}\right)}
$$

where

$$
\alpha_{\nu}=\sqrt{\frac{2(r+\delta)}{\sigma^{2}}+\left(\frac{1}{2}+\nu\right)^{2}}+\nu-\frac{1}{2} .
$$


Proof. See Section 6.6 in the appendix.

Writing down the first-order conditions for the equilibrium $(\kappa, \nu)$ - equivalently, the ones that maximize $P$ - is not very informative. Figure 7 compares optimal repayment schedules in the cases in which contracts are flat, log-linear, and piecewise log-linear with one kink $^{13}$.

\section{[Figure 7 About Here]}

It is interesting to notice that for these parameter values, repayment ratios become optimally larger than 1 in the long run even though the income process has no drift and there is no inflation risk in our environment. ${ }^{14}$ The log-linear contract features increasing repayments. So does the one with a kink after a short series of high and then decreasing initial repayments that can be interpreted as an initial downpayment. These repayment patterns are reminiscent of the "teaser rates" that often apply in practice. Such schedules are optimal because households' expected income at remote dates conditionally on still honoring repayments stochastically increases over time. ${ }^{15}$

Figure 8 illustrates equilibrium loan-to-income ratios with these three types of contracts as a function of $\delta$.

[Figure 8 About Here]

As $\delta$ becomes small, the fixed-repayment contract does quite poorly. As contracting relationships become longer-lived, suboptimal repayment schedules become more costly. For $\delta$ around $5 \%$, loan-to-income ratios increase by less than $5 \%$ when adding a drift, and less than $1 \%$ by allowing for a kink. This suggests that the restriction to fixed-repayment contracts is not an important driver of our findings.

\section{Concluding Remarks}

We have developed an analytically tractable model in which contracting frictions drive equilibrium default and refinancing intensities, debt capacities, and asset prices. In light of the

\footnotetext{
${ }^{13}$ Closed-form solutions for the loan-to-income ratio with the piecewise linear contract are available upon request.

${ }^{14}$ Optimal repayment schedules are decreasing for larger values of $\delta$.

${ }^{15}$ Numerical solutions for contracts that allow more than one kink generate very similar patterns as the one we obtain for one kink and these parameter values.
} 
current U.S. housing crisis, the model generates interesting insights into the impact of lower refinancing costs and bubbles on these equilibrium outcomes. There are at least two interesting routes for future research.

First, our model can be estimated in principle, and its rich set of predictions can be tested using household-level data. A number of our simplifying assumptions can be relaxed for the purpose of estimation. For example, we have assumed that households always exhaust their debt capacities, which results in a uniform repayment ratio for all households. We could specify instead indirect aggregate household preferences by using a distribution of repayment ratios observed in the data, or any other distribution. Similarly, we could allow for heterogeneity in refinancing costs and in idiosyncratic income volatility.

Second, our framework is a versatile description of an economy with borrowing constraints that could be useful in contexts other than housing markets. It could be applied to study the behavior of other information-problematic borrowers, such as small businesses and entrepreneurs.

\section{Appendix}

\subsection{Lemma 1}

This section states and proves Lemma 1 that we apply throughout. Assume that a household $j \in[0,1]$ accepts a loan at date $t$ that specifies a repayment of $\kappa I_{j, t} e^{-\sigma^{2} \nu \tau}$ at each future date $t+\tau$, with $(\kappa, \nu) \in(0,1) \times \mathbb{R}$. Assume that the household does not renegotiate on its loan $(c=+\infty)$. The loan contract is thus terminated at the random date $t+T^{j, t}$, where

$$
T^{j, t}=\min \left(T_{\delta}^{j, t}, T_{\kappa}^{j, t}\right)
$$

The random variable $T_{\delta}^{j, t}$ is the first ET date occuring after $t$ :

$$
T_{\delta}^{j, t}=\min \aleph_{j} \cap(t,+\infty),
$$


and $T_{\kappa}^{j, t}$ is defined as

$$
\left\{T_{\kappa}^{j, t}=\tau\right\} \Longleftrightarrow \widetilde{W}_{j, \tau} \equiv \phi\left(W_{t+\tau}-W_{t}\right)+\sqrt{1-\phi^{2}}\left(W_{j, t+\tau}-W_{j, t}\right)=\frac{\ln (\kappa)}{\sigma}+\left(\frac{1}{2}-\nu\right) \sigma \tau
$$

The random variables $T^{j, t}, T_{\delta}^{j, t}, T_{\kappa}^{j, t}$ are stopping times for $\left(\mathcal{F}_{t}\right)_{t \geq 0}$. Since their distributions do not depend on when and to whom the loan was granted, we will omit the superscripts $j, t$ on these variables in what follows. We have the following result:

\section{Lemma 1}

Let

$$
\begin{aligned}
& \alpha_{\nu}=\sqrt{\frac{2(r+\delta)}{\sigma^{2}}+\left(\frac{1}{2}+\nu\right)^{2}}+\nu-\frac{1}{2} \\
& \beta_{\nu}=\sqrt{\frac{2(r+\delta)}{\sigma^{2}}+\left(-\frac{1}{2}+\phi^{2}+\nu\right)^{2}}+\nu-\frac{1}{2}+\phi^{2} .
\end{aligned}
$$

We have

$$
\begin{aligned}
E\left(\int_{0}^{T} e^{-\left(r+\nu \sigma^{2}\right) s} d s\right) & =\frac{1-\kappa^{\alpha_{v}}}{r+\delta+\nu \sigma^{2}}, \\
E_{t}\left(e^{-r T} 1_{\left\{T_{\delta}>T_{\kappa}\right\}} I_{t+T}\right) & =\kappa^{\beta_{\nu}} I_{t}, \\
E_{t}\left(e^{-r T} 1_{\left\{T_{\delta} \leq T_{\kappa}\right\}} I_{t+T}\right) & =\frac{\delta\left(1-\kappa^{\beta}\right)}{r+\delta} I_{t} .
\end{aligned}
$$

Proof. We will use the following auxiliary results:

1. The density of $T_{\kappa}$ is

$$
\varphi_{\kappa}(t)=\frac{a}{\sqrt{2 \pi t^{3}}} e^{\frac{-(a+\mu t)^{2}}{2 t}}
$$

where

$$
a=-\frac{\ln (\kappa)}{\sigma}, \mu=\sigma\left(\nu-\frac{1}{2}\right) .
$$

Its Laplace transform is

$$
e^{-\mu a-a \sqrt{2 s+\mu^{2}}}=\kappa^{\frac{\mu}{\sigma}+\sqrt{\frac{2 s+\mu^{2}}{\sigma^{2}}}} .
$$

Proof. See, e.g., Borodin and Salminen (2002). 
2. Let $X$ be a random variable independent from $T_{\delta}$ taking values in $[0,+\infty) \cup\{+\infty\}$ whose density has Laplace transform $\mathcal{L}($.$) . Define T_{\min }=\min \left(X, T_{\delta}\right)$. Then the Laplace transform of the density of $T_{\min }$ is given by

$$
\frac{s \mathcal{L}(s+\delta)+\delta}{s+\delta} .
$$

Proof. Straightforward computations

3. The Laplace transform of the density of $T$ is

$$
\mathcal{L}_{d}(s)=\frac{s \kappa^{\frac{\mu}{\sigma}+\sqrt{\frac{2(s+\delta)+\mu^{2}}{\sigma^{2}}}}+\delta}{s+\delta}
$$

Proof. From 1. and 2.

4. Let $B_{t}$ be a standard Wiener process. Define the running minimum as

$$
M_{t}=\min _{0 \leq s \leq t} B_{s}
$$

For $t>0$ and $x \geq y, y \leq 0$,

$$
\operatorname{Prob}\left[B_{t} \in d x, M_{t} \in d y\right]=\frac{2(x-2 y)}{\sqrt{2 \pi t^{3}}} e^{-\frac{(x-2 y)^{2}}{2 t}} .
$$

Proof. See Borodin and Salminen (2002)

5. Fix $t \geq 0$ and $y \in \mathbb{R}$. For all $\tau \geq 0$, define the measure $Q_{\tau}$ as

$$
\forall A \in \mathcal{F}_{t+\tau}, Q_{\tau}(A)=E_{t}\left(1_{A} \times e^{-\mu \widetilde{W}_{j, \tau}-\frac{\mu^{2} \tau}{2}}\right)
$$

We have:

$$
\left.E_{t}^{Q_{\tau}}\left[I_{t+\tau} \mid \widetilde{W}_{j, \tau}+\mu \tau=y\right] ; \sigma\left(I_{j, t+s}, 0 \leq s \leq \tau\right)\right]=e^{\phi^{2} \sigma y+\sigma^{2} \phi^{2}\left(1-\phi^{2}\right) \tau t / 2-\phi^{2} \sigma^{2} \nu \tau},
$$

where

$$
\widetilde{W}_{j, \tau}=\phi\left(W_{t+\tau}-W_{t}\right)+\sqrt{1-\phi^{2}}\left(W_{j, t+\tau}-W_{j, t}\right) .
$$

Proof. Note first that 


$$
E_{t}^{Q_{\tau}}\left[I_{t+\tau} \mid \widetilde{W}_{j, \tau}+\mu \tau=y ; \sigma\left(I_{j, t+s}, 0 \leq s \leq \tau\right)\right]=E_{t}^{Q_{\tau}}\left[I_{t+\tau} \mid \widetilde{W}_{j, \tau}+\mu \tau=y\right]
$$

From Girsanov theorem, viewed from date $t$

$$
W_{t+\tau}-W_{t}+\phi \mu \tau \mid \widetilde{W}_{j, \tau}+\mu \tau=y \sim N\left(\phi y,\left(1-\phi^{2}\right) \tau\right) \text { under } Q_{\tau}
$$

Therefore,

$$
\sigma \phi\left(W_{t+\tau}-W_{t}+\phi \mu \tau\right) \mid \widetilde{W}_{j, \tau}+\mu \tau=y \sim N\left(\sigma \phi^{2} y, \sigma^{2} \phi^{2}\left(1-\phi^{2}\right) \tau\right) \text { under } Q_{\tau}
$$

Thus,

$$
E_{t}^{Q_{\tau}}\left[I_{t+\tau} \mid \widetilde{W}_{j, \tau}+\mu \tau=y\right]=I_{t} e^{\phi^{2} \sigma y+\sigma^{2} \phi^{2}\left(1-\phi^{2}\right) \tau / 2-\sigma \phi^{2} \mu \tau-\phi^{2} \sigma^{2} \frac{\tau}{2}} .
$$

From $\mu=\sigma(\nu-1 / 2)$, we finally obtain

$$
E_{t}^{Q_{\tau}}\left[I_{t+\tau} \mid \widetilde{W}_{j, \tau}+\mu \tau=y\right]=e^{\phi^{2} \sigma y+\sigma^{2} \phi^{2}\left(1-\phi^{2}\right) \tau / 2-\phi^{2} \sigma^{2} \nu \tau}
$$

6. We have

$$
E_{t}\left[I_{t+\tau} \mid I_{j, t+\tau}=\kappa I_{j, t}\right]=I_{t} \kappa^{\phi^{2}} e^{\sigma^{2} \phi^{2}\left(1-\phi^{2}\right) \tau / 2-\phi^{2} \sigma^{2} \nu \tau} .
$$

Proof. Viewed from date $t$

$$
W_{t+\tau}-W_{t}+\phi \mu \tau \mid \widetilde{W}_{j, \tau}+\mu \tau=\frac{\ln \kappa}{\sigma} \sim N\left(\phi \frac{\ln \kappa}{\sigma},\left(1-\phi^{2}\right) \tau\right)
$$

Thus,

$$
E_{t}\left[I_{t+\tau} \mid I_{j, t+\tau}=\kappa I_{j, t}\right]=I_{t} e^{\phi^{2} \sigma \frac{\ln \kappa}{\sigma}+\sigma^{2} \phi^{2}\left(1-\phi^{2}\right) \tau / 2-\sigma \phi^{2} \mu \tau-\phi^{2} \sigma^{2} \frac{\tau}{2}} .
$$

Replacing $\mu=\sigma(\nu-1 / 2)$ yields

$$
E_{t}\left[I_{t+\tau} \mid I_{j, t+\tau}=\kappa I_{j, t}\right]=I_{t} \kappa^{\phi^{2}} e^{\sigma^{2} \phi^{2}\left(1-\phi^{2}\right) \tau / 2-\phi^{2} \sigma^{2} \nu \tau}
$$


Using these results, we first compute $E_{t}\left(\int_{0}^{T} e^{-\left(r+\nu \sigma^{2}\right) s} d s\right)$. Denoting $\varphi($.$) the density of$ $T$, we have

$$
\begin{aligned}
E_{t}\left(\int_{0}^{T} e^{-\left(r+\nu \sigma^{2}\right) s} d s\right) & =\int_{0}^{+\infty}\left(\frac{1-e^{-\left(r+\nu \sigma^{2}\right) t}}{r+\nu \sigma^{2}}\right) \varphi(t) d t \\
& =\frac{1}{r+\nu \sigma^{2}}\left(1-\mathcal{L}_{d}\left(r+\nu \sigma^{2}\right)\right)
\end{aligned}
$$

Using (6.3), we obtain

$$
E_{t}\left(\int_{0}^{T} e^{-\left(r+\nu \sigma^{2}\right) s} d s\right)=\frac{1-\kappa^{\alpha_{v}}}{r+\delta+\nu \sigma^{2}}
$$

We now compute $E_{t}\left(e^{-r T} 1_{\left\{T_{\delta}>T_{\kappa}\right\}} I_{t+T}\right)$.

Let us introduce a family of stopping times $\left(T_{d, \tau}\right)_{\tau \geq 0}=\left(\min \left(T_{\kappa}, \tau\right)\right)_{\tau \geq 0}$. Then

$$
E_{t}\left(e^{-r T} 1_{\left\{T_{\delta}>T_{\kappa}\right\}} I_{t+T}\right)=\int_{0}^{\infty} \delta e^{-\delta \tau} E_{t}\left[I_{t+T_{d, \tau}} e^{-r T_{d, \tau}} \mathbf{1}_{\left\{T_{d, \tau}<\tau\right\}} \mid I_{j, t+T_{d, \tau}}=\kappa I_{j, t}\right] d \tau
$$

By (6.8)

$$
E_{t}\left[I_{t+T_{d, \tau}} e^{-r T_{d, \tau}} \mathbf{1}_{\left\{T_{d, \tau}<\tau\right\}} \mid I_{j, t+T_{d, \tau}}=\kappa I_{j, t}\right]=I_{t} e^{-r T_{d, \tau}} \kappa^{\phi^{2}} e^{\sigma^{2} \phi^{2}\left(1-\phi^{2}\right) \frac{T_{d, \tau}}{2}-\phi^{2} \sigma^{2} \nu T_{d, \tau}}
$$

Therefore, using (6.1) we arrive at

$$
E_{t}\left(e^{-r T} 1_{\left\{T_{\delta}>T_{\kappa}\right\}} I_{t+T}\right)=I_{t} \kappa^{\phi^{2}} \delta \int_{0}^{\infty} e^{-\left(\delta+r-\frac{\sigma^{2} \phi^{2}\left(1-\phi^{2}\right)}{2}+\phi^{2} \sigma^{2} \nu\right) \tau} \varphi_{\kappa}(\tau) d \tau=I_{t} \kappa^{\beta_{\nu}}
$$

Finally, we compute $E_{t}\left(e^{-r T} \mathbf{1}_{\left\{T_{\kappa} \geq T_{\delta}\right\}} \cdot I_{t+T}\right)$. We have

$$
E_{t}\left(e^{-r T} \cdot \mathbf{1}_{\left\{T_{\kappa} \geq T_{\delta}\right\}} \cdot I_{t+T}\right)=\int_{0}^{\infty} \delta e^{-\delta \tau} e^{-r \tau} E_{t}\left[I_{t+\tau} \mathbf{1}_{\left\{T_{d, \tau}=\tau\right\}}\right] d \tau .
$$

Notice that

$$
\left\{T_{d, \tau}=\tau\right\}=\left\{\min _{0 \leq s \leq \tau} \widetilde{W}_{s}+\mu s>\frac{\ln (\kappa)}{\sigma}\right\} \quad \text { a.s. }
$$

By Girsanov Theorem, (6.4), and (6.5) we have

$$
E_{t}\left(I_{t+\tau} \mathbf{1}_{\left\{T_{d, \tau}=\tau\right\}}\right)=I_{t} \int_{\frac{\ln (\kappa)}{\sigma}}^{0} \int_{y}^{\infty} \frac{2(x-2 y)}{\sqrt{2 \pi \tau^{3}}} e^{-\frac{(x-2 y)^{2}}{2 \tau}} e^{\phi^{2} \sigma x+\sigma^{2} \phi^{2}\left(1-\phi^{2}\right) \frac{\tau}{2}-\phi^{2} \sigma^{2} \nu \tau} e^{\mu x-\frac{\mu^{2}}{2} \tau} d x d y
$$




$$
=I_{t} \int_{\frac{\ln (\kappa)}{\sigma}}^{0} \int_{0}^{\infty} \frac{2(x-y)}{\sqrt{2 \pi \tau^{3}}} e^{-\frac{(x-y)^{2}}{2 \tau}} e^{\phi^{2} \sigma(x+y)+\sigma^{2} \phi^{2}\left(1-\phi^{2}\right) \frac{\tau}{2}-\phi^{2} \sigma^{2} \nu \tau} e^{\mu(x+y)-\frac{\mu^{2}}{2} \tau} d x d y .
$$

Using (6.1) we have

$$
\begin{aligned}
\int_{0}^{\infty} \delta e^{-\left(\delta+r-\frac{\sigma^{2} \phi^{2}\left(1-\phi^{2}\right)}{2}+\phi^{2} \sigma^{2} \nu+\frac{\mu^{2}}{2}\right) \tau} \frac{2(x-y)}{\sqrt{2 \pi \tau^{3}}} e^{-\frac{(x-y)^{2}}{2 \tau}} d \tau & =2 \delta e^{-\sqrt{2(r+\delta)-\sigma^{2} \phi^{2}\left(1-\phi^{2}\right)+2 \phi^{2} \sigma^{2} \nu+\mu^{2}}(x-y)} \\
& =2 \delta e^{-\sqrt{2(r+\delta)+\sigma^{2}\left(-\frac{1}{2}+\phi^{2}+\nu\right)^{2}}(x-y)}, \quad x \geq y .
\end{aligned}
$$

By Fubini's theorem

$$
\begin{gathered}
E_{t}\left(e^{-r T} \mathbf{1}_{\left\{T_{\kappa} \geq T_{\delta}\right\}} I_{t+T}\right)=\delta I_{t} \int_{\frac{\ln (\kappa)}{\sigma}}^{0} \int_{0}^{\infty} e^{-\sqrt{2(r+\delta)+\sigma^{2}\left(-\frac{1}{2}+\phi^{2}+\nu\right)^{2}}(x-y)} e^{\left(\phi^{2} \sigma+\mu\right)(y+x)} d x d y \\
E_{t}\left(e^{-r T} \mathbf{1}_{\left\{T_{\kappa} \geq T_{\delta}\right\}} I_{t+T}\right)=\frac{\delta I_{t}}{r+\delta}\left(1-\kappa^{-\frac{1}{2}+\phi^{2}+\nu+\sqrt{\frac{2(r+\delta)}{\sigma^{2}}+\left(-\frac{1}{2}+\phi^{2}+\nu\right)^{2}}}\right) .
\end{gathered}
$$

\subsection{Proofs of Section 2.2}

We use the following mathematical results. Let

$$
a=-\frac{\ln \kappa}{\sigma}, b=\frac{\ln (1+c)}{\sigma}
$$

For all $s>0$,

$$
\begin{aligned}
E\left(e^{-s T_{c}} \mathbf{1}_{\left\{T_{c}<T_{\kappa}\right\}}\right) & =\frac{\sinh \left(a \sqrt{2 s+\frac{\sigma^{2}}{4}}\right)}{\sinh \left((b+a) \sqrt{2 s+\frac{\sigma^{2}}{4}}\right)} e^{\frac{\sigma b}{2}}, \\
E\left(e^{-s T_{\kappa}} \mathbf{1}_{\left\{T_{\kappa}<T_{c}\right\}}\right) & =\frac{\sinh \left(b \sqrt{2 s+\frac{\sigma^{2}}{4}}\right)}{\sinh \left((b+a) \sqrt{2 s+\frac{\sigma^{2}}{4}}\right)} e^{-\frac{\sigma a}{2}} .
\end{aligned}
$$

These formulae can be found in Borodin and Salminen (2002).

Proof of Proposition 2. We need to compute the expressions of $E\left(e^{-r T_{\kappa}} \mathbf{1}_{\left\{T_{\kappa}<T_{c}, T_{\kappa}<T_{\delta}\right\}}\right)$ 
and $1-E_{t} e^{-r T}$ to complete the proof. We have

$$
E\left(e^{-r T_{\kappa}} \mathbf{1}_{\left\{T_{\kappa}<T_{c}, T_{\kappa}<T_{\delta}\right\}}\right)=\frac{\sinh \left(b \sqrt{2(r+\delta)+\frac{\sigma^{2}}{4}}\right)}{\sinh \left((b+a) \sqrt{2(r+\delta)+\frac{\sigma^{2}}{4}}\right)} e^{-\frac{\sigma a}{2}}
$$

To see this, let $\varphi_{\kappa}($.$) and \varphi_{c}($.$) denote the respective densities of T_{\kappa}$ and $T_{c}$. Note that

$$
\begin{aligned}
E\left(e^{-r T_{\kappa}} \mathbf{1}_{\left\{T_{\kappa}<T_{c}, T_{\kappa}<T_{\delta}\right\}}\right) & =\int_{0}^{+\infty} e^{-\delta t} e^{-r t} \times E\left(\mathbf{1}_{\left\{T_{c}>t\right\}}\right) \times \varphi_{\kappa}(t) d t \\
& =E\left(e^{-(r+\delta) T_{\kappa}} \mathbf{1}_{\left\{T_{\kappa}<T_{c}\right\}}\right)
\end{aligned}
$$

Equation (6.17) stems then from (6.16) with $s=r+\delta$.

We also have

$$
1-E_{t} e^{-r T}=\frac{r}{r+\delta}\left(1-\frac{\sinh \left(a \sqrt{2(r+\delta)+\frac{\sigma^{2}}{4}}\right)}{\sinh \left((b+a) \sqrt{2(r+\delta)+\frac{\sigma^{2}}{4}}\right)} e^{\frac{\sigma b}{2}}-\frac{\sinh \left(b \sqrt{2(r+\delta)+\frac{\sigma^{2}}{4}}\right)}{\sinh \left((b+a) \sqrt{2(r+\delta)+\frac{\sigma^{2}}{4}}\right)} e^{-\frac{\sigma a}{2}}\right) .
$$

To see this, note that

$$
E_{t} e^{-r T}=E\left(e^{-r T_{c}} \mathbf{1}_{\left\{T_{c}<T_{\kappa}, T_{c}<T_{\delta}\right\}}\right)+E\left(e^{-r T_{\kappa}} \mathbf{1}_{\left\{T_{\kappa}<T_{c}, T_{\kappa}<T_{\delta}\right\}}\right)+E\left(e^{-r T_{\delta}} \mathbf{1}_{\left\{T_{\delta}<T_{\kappa}, T_{\delta}<T_{c}\right\}}\right),
$$

and

$$
\begin{aligned}
E\left(e^{-r T_{\kappa}} \mathbf{1}_{\left\{T_{\kappa}<T_{c}, T_{\kappa}<T_{\delta}\right\}}\right)= & \int_{0}^{+\infty} e^{-\delta t} e^{-r t} \times E\left(\mathbf{1}_{\left\{T_{c}>t\right\}}\right) \times \varphi_{\kappa}(t) d t \\
E\left(e^{-r T_{c}} \mathbf{1}_{\left\{T_{\kappa}<T_{c}, T_{\kappa}<T_{\delta}\right\}}\right)= & \int_{0}^{+\infty} e^{-\delta t} e^{-r t} \times E\left(\mathbf{1}_{\left\{T_{\kappa}>t\right\}}\right) \times \varphi_{c}(t) d t \\
E\left(e^{-r T_{\delta}} \mathbf{1}_{\left\{T_{\delta}<T_{c}, T_{\delta}<T_{\kappa}\right\}}\right)= & \int_{0}^{+\infty} \delta e^{-(r+\delta) t} E\left[\mathbf{1}_{\left\{T_{\kappa}>t\right\}} \times \mathbf{1}_{\left\{T_{c}>t\right\}}\right] d t \\
= & \int_{0}^{+\infty} \frac{\delta}{r+\delta}\left(1-e^{-(r+\delta) t}\right) E\left(\mathbf{1}_{\left\{T_{\kappa}>t\right\}}\right) \times \varphi_{\kappa}(t) d t \\
& +\int_{0}^{+\infty} \frac{\delta}{r+\delta}\left(1-e^{-(r+\delta) t}\right) E\left(\mathbf{1}_{\left\{T_{c}>t\right\}}\right) \times \varphi_{c}(t) d t .
\end{aligned}
$$

Re-arranging and writing (6.15) and (6.16) with $s=r+\delta$ yields (6.18). Plugging (6.17) and 
(6.18) into (2.12) and re-arranging yields (2.11).

Proof of formulae (2.15) and (2.16) in Proposition 4. From (6.15) and (6.16),

$$
\begin{aligned}
& p_{c}=\operatorname{Prob}\left(T_{c}<T_{\kappa} ; T_{c}<T_{\delta}\right)=E\left(e^{-\delta T_{c}} \mathbf{1}_{\left\{T_{c}<T_{\kappa}\right\}}\right)=\frac{\sinh \left(a \sqrt{2 \delta+\frac{\sigma^{2}}{4}}\right)}{\sinh \left((b+a) \sqrt{2 \delta+\frac{\sigma^{2}}{4}}\right)} e^{\frac{\sigma b}{2}} \\
& p_{\kappa}=\operatorname{Prob}\left(T_{\kappa}<T_{c} ; T_{\kappa}<T_{\delta}\right)=E\left(e^{-\delta T_{\kappa}} \mathbf{1}_{\left\{T_{\kappa}<T_{c}\right\}}\right)=\frac{\sinh \left(b \sqrt{2 \delta+\frac{\sigma^{2}}{4}}\right)}{\sinh \left((b+a) \sqrt{2 \delta+\frac{\sigma^{2}}{4}}\right)} e^{-\frac{\sigma a}{2}}
\end{aligned}
$$

\subsection{Proof of Proposition 6}

Assume that the equilibrium price $\left(P_{t}\right)_{t \geq 0}$ is a positive process that satisfies the transversality condition (3.1). Let $\kappa$ denote the equilibrium repayment ratio. Market clearing implies

$$
P_{t}=\frac{\kappa\left(1-\kappa^{\alpha}\right)}{r+\delta} I_{t}+E_{t}\left[e^{-r T}\left(1-\lambda 1_{\left\{T_{\delta}>T_{\kappa}\right\}}\right) P_{t+T}\right]
$$

where $T, T_{\delta}, T_{\kappa}$ are the stopping times introduced in the proof of Proposition 1 . Further, we have seen in the proof of Proposition 1 that

$$
E_{t}\left[e^{-r T}\left(1-\lambda 1_{\left\{T_{\delta}>T_{\kappa}\right\}}\right) I_{t+T}\right]=\frac{r \rho \kappa^{1+\alpha}+\delta}{r+\delta} I_{t}
$$

so that

$$
\begin{aligned}
P_{t}= & \frac{\kappa\left(1-\kappa^{\alpha}\right)}{r+\delta}\left(1+\frac{r \rho \kappa^{1+\alpha}+\delta}{r+\delta}\right) I_{t}+ \\
& E_{t}\left[e^{-r\left(T+T^{\prime}\right)}\left(1-\lambda 1_{\left\{T_{\delta}>T_{\kappa}\right\}}\right)\left(1-\lambda 1_{\left\{T_{\delta}^{\prime}>T_{\kappa}^{\prime}\right\}}\right) P_{t+T+T^{\prime}}\right]
\end{aligned}
$$

where $T^{\prime}, T_{\delta}^{\prime}, T_{\kappa}^{\prime}$ are the stopping times associated with the second contractual relationship after $t$, independent from $\left(T, T_{\delta}, T_{\kappa}\right)$. Clearly, iterating further and applying the transversality condition yields that the price must be linear with respect to $I_{t}$. Moreover, Proposition 1 establishes that there is a unique linear equilibrium. 


\subsection{Proof of Proposition 8}

Proof of Equation (3.6). A price of the form (3.5) clears the market in the presence of such loan contracts if and only if:

$$
F\left(I_{t}\right)=E_{t}\left[\mathbf{1}_{\left\{T_{\kappa} \geq T_{\delta}\right\}} e^{-r T_{\delta}} F\left(I_{t+T_{\delta}}\right)+\lambda \mathbf{1}_{\left\{T_{\kappa}<T_{\delta}\right\}} e^{-r T_{\kappa}} F\left(I_{t+T_{\kappa}}\right)\right] .
$$

A straightforward modification of (6.11) yields:

$$
E_{t}\left[\mathbf{1}_{\left\{T_{\kappa}<T_{\delta}\right\}} e^{-r T_{\delta}} F\left(I_{t+T_{\delta}}\right)\right]=F\left(\kappa I_{t}\right) E_{t}\left[\mathbf{1}_{\left\{T_{\kappa}<T_{\delta}\right\}} e^{-r T_{\kappa}}\right]=F\left(\kappa I_{t}\right) \kappa^{\alpha}
$$

Next, we compute $E_{t}\left[\mathbf{1}_{\left\{T_{\kappa} \geq T_{\delta}\right\}} e^{-r T_{\delta}} F\left(I_{t+T_{\delta}}\right)\right]$. A straightforward modification of (6.13) yields:

$$
E_{t}\left[\mathbf{1}_{\left\{T_{\kappa} \geq T_{\delta}\right\}} e^{-r T_{\delta}} F\left(I_{t+T_{\delta}}\right)\right]=2 \delta \int_{\frac{\ln (\kappa)}{\sigma}}^{0} \int_{0}^{\infty} e^{-\sqrt{2(r+\delta)+\frac{1}{4} \sigma^{2}}(x-y)} F\left(I_{t} e^{\sigma(x+y)}\right) e^{-\frac{1}{2} \sigma(x+y)} d x d y .
$$

Changing variables $w=x+y$ and $u=x-y$, we can rewrite (6.20) as

$E_{t}\left[\mathbf{1}_{\left\{T_{\kappa} \geq T_{\delta}\right\}} e^{-r T_{\delta}} F\left(I_{t+T_{\delta}}\right)\right]=\delta\left(\int_{\frac{\ln (\kappa)}{\sigma}}^{0} \int_{-w}^{w-2 \frac{\ln (\kappa)}{\sigma}}+\int_{0}^{\infty} \int_{w}^{w-2 \frac{\ln (\kappa)}{\sigma}}\right) F\left(I_{t} e^{\sigma w}\right) e^{-\frac{1}{2} \sigma w} e^{-\sqrt{2(r+\delta)+\frac{1}{4} \sigma^{2}} u} d u d w$

And

$$
\begin{gathered}
\delta \int_{0}^{\infty} \int_{w}^{w-2 \frac{\ln (\kappa)}{\sigma}} F\left(I_{t} e^{\sigma w}\right) e^{-\frac{1}{2} \sigma w} e^{-\sqrt{2(r+\delta)+\frac{1}{4} \sigma^{2}} u} d u d w \\
=\frac{2 \delta\left(1-\kappa^{2 \alpha+1}\right)}{\sigma(2 \alpha+1)} \int_{0}^{\infty} F\left(I_{t} e^{\sigma w}\right) e^{-\sigma(1+\alpha) w} d w=\frac{2 \delta}{(2 \alpha+1) \sigma^{2}} \int_{1}^{\infty} F\left(I_{t} y\right) y^{-(2+\alpha)} d y .
\end{gathered}
$$

Finally,

$$
\begin{gathered}
\delta \int_{\frac{\ln (\kappa)}{\sigma}}^{0} \int_{-w}^{w-2 \frac{\ln (\kappa)}{\sigma}} F\left(I_{t} e^{\sigma w}\right) e^{-\frac{1}{2} \sigma w} e^{-\sqrt{2(r+\delta)+\frac{1}{4} \sigma^{2}} u} d u d w= \\
=\frac{2 \delta}{(2 \alpha+1) \sigma^{2}} \int_{\kappa}^{1} F\left(I_{t} y\right)\left(y^{\alpha-1}-y^{-(2+\alpha)} \kappa^{2 \alpha+1}\right) d y .
\end{gathered}
$$

Summing up (6.19), (6.21), and (6.22) yields (3.6)

Proof of Equation (3.7). A repayment ratio $\kappa$ maximizes the right-hand side of (3.6) 
and thus expected loan repayments $\kappa$ if and only if

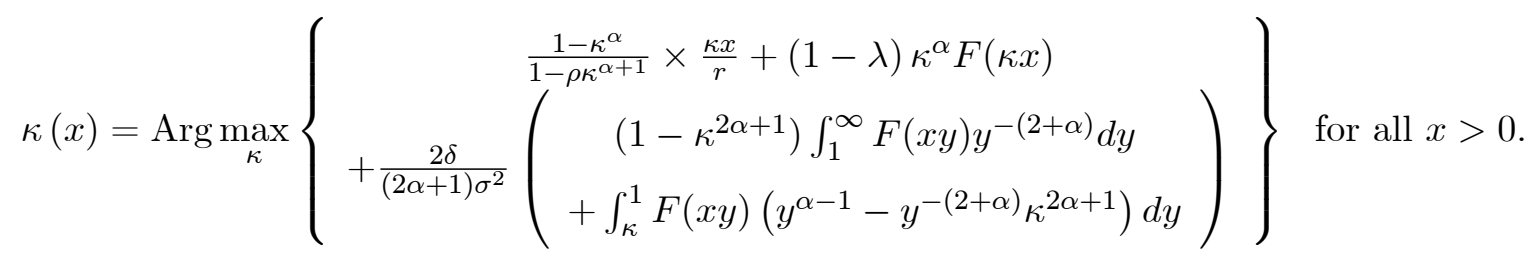

The first-order condition associated with this maximization problem is $(3.7)$

\subsection{Proof of Proposition 10}

Clearing the market for vacant homes in the presence of such contracts yields:

$P=\kappa E_{t}\left(\int_{0}^{\min \left(T_{\delta}, T_{g}\right)} e^{-r s-g(s)} d s\right)+(1-\lambda) P \times E_{t}\left(e^{-r T_{g}} 1_{\left\{T_{\delta}>T_{g}\right\}}\right)+P \times E_{t}\left(e^{-r T_{\delta}} 1_{\left\{T_{\delta} \leq T_{g}\right\}}\right)$.

We have

$$
\begin{aligned}
E_{t}\left(\int_{0}^{\min \left(T_{\delta}, T_{g}\right)} e^{-r s-g(s)} d s\right) & =\int_{0}^{+\infty}-\frac{d}{d t}\left(e^{-\delta t} Q_{g}(t)\right) \int_{0}^{t} e^{-r s-g(s)} d s=\int_{0}^{+\infty} Q_{g}(s) e^{-(r+\delta) s-g(s)} d s, \\
E_{t}\left(e^{-r T_{g}} 1_{\left\{T_{\delta}>T_{g}\right\}}\right) & =\int_{0}^{+\infty} \frac{d}{d t}\left[1-Q_{g}(t)\right] \times e^{-\delta t} e^{-r t} d t=(r+\delta) \int_{0}^{+\infty}\left(1-Q_{g}(t)\right) e^{-(r+\delta) t} d t \\
E_{t}\left(e^{-r T_{\delta}} 1_{\left\{T_{\delta} \leq T_{g}\right\}}\right) & =\int_{0}^{+\infty} \delta e^{-\delta t} Q_{g}(t) e^{-r t} d t .
\end{aligned}
$$

Solving for $P$ yields the proposition.

\subsection{Proof of Proposition 11}

With the same notations as in the previous sections, clearing the market for vacant homes in the presence of such contracts yields:

$$
P=\kappa E_{t}\left(\int_{0}^{T} e^{-r s} d s\right)+(1-\lambda) P \times E_{t}\left(e^{-r T} 1_{\left\{T_{\delta}>T_{\kappa}\right\}}\right)+P \times E_{t}\left(e^{-r T} 1_{\left\{T_{\delta} \leq T_{\kappa}\right\}}\right) .
$$

Applying Lemma 1 with $\phi=0$ gives the values of the right-hand side expectations, and solving for $P$ yields the Proposition. 


\section{References}

[1] Heitor Almeida, Murillo Campello, Crocker Liu,"The Financial Accelerator: Evidence from International Housing Markets", The Review of Finance, Vol. 10, No. 3 (2006), pp. $321-352$

[2] Fernando Alvarez, Urban Jermann,"Efficiency, Equilibrium, and Asset Pricing with Risk of Default", Econometrica, Vol. 68, No. 4 (2000), pp. 775-797

[3] Ben Bernanke, Mark Gertler,"Agency Costs, Net Worth, and Business Fluctuations", The American Economic Review, Vol. 79, No. 1 (1989), pp. 14-31

[4] Olivier Blanchard, Mark Watson, "Bubbles, Rational Expectations and Financial Markets", NBER Working Paper No. W0945, (1982)

[5] Andrei Borodin,Paavo Salminen, "Handbook of Brownian Motion - Facts and Formulae", Second Edition, Birkhauser Verlag AG (2002)

[6] Yongheng Deng, Stuart Gabriel, Frank Northaft,"Duration of Residence in the Rental Housing Markets", Journal of Real Estate Finance and Economics, Vol. 26, No. 2-3 (2003), pp. 268-281

[7] Karen Dynan, Douglas Elmendorf, Daniel Sichel,"The Evolution of Household Income Volatility", Brooking Papers on Economic Activity, Spring 2008

[8] Frank Fabozzi,"The Handbook of Mortgage-Backed Securities", McGraw-Hill Professional, $6^{\text {th }}$ edition $(2006)$

[9] Kenneth Froot, Maurice Obstfeld,"Intrinsic Bubbles: The Case of Stock Prices", The American Economic Review, Vol. 81, No. 5 (1991), pp. 1189-1214

[10] Douglas Gale, Martin Hellwig,"Incentive-Compatible Debt Contracts: The One-Period Problem", The Review of Economic Studies, Vol. 52, No. 4 (1985), pp. 647-663

[11] Gary Gorton,"The Subrpime Panic", NBER working paper \#14398

[12] Christian Hellwig, Guido Lorenzoni,"Bubbles and Self-Enforcing Debt", working paper, $\operatorname{MIT}(2008)$ 
[13] Timothy J. Kehoe, David K. Levine,"Liquidity Constrained Markets versus Debt Constrained Markets", Econometrica, Vol. 69, No. 3 (2001), pp. 575-598

[14] Ben Keys, Tanmoy Mukherjee, Amit Seru, Vikrant Vig, "Did Securitization Lead to Lax Screening? Evidence from Subprime Loans", working paper, University of Chicago GSB (2008)

[15] Nobuhiro Kiyotaki, John Moore,"Credit Cycles", The Journal of Political Economy, Vol. 105, No. 2 (1997), pp. 211-248

[16] Dirk Krueger, Harald Uhlig, "Competitive Risk Sharing Contracts with One-Sided Commitment", Journal of Monetary Economics, Vol. 53, No. 7 (2006), pp.1661-1691

[17] Owen Lamont, Jeremy Stein,"Leverage and House-Price Dynamics in U.S. Cities", The RAND Journal of Economics, Vol. 30, No. 3 (1999), pp. 498-514

[18] Atif Mian, Amir Sufi,"The Consequences of Mortgage Credit Expansion: Evidence from the U.S. Mortgage Default Crisis", Quarterly Journal of Economics, forthcoming

[19] Francois Ortalo-Magné, Sven Rady,"Housing Market Dynamics: On the Contribution of Income Shocks and Credit Constraints", The Review of Economic Studies, Vol. 73, No. 2 (2006), pp. 459-485

[20] Tomask Piskorski, Alexei Tchistyi,"Stochastic House Appreciation and Optimal Mortgage Lending", working paper, Columbia Business School (2008)

[21] Jean-Charles Rochet, "Lending Booms and Sudden Stops: Why do Countries Default?", working paper, Toulouse School of Economics (2007)

[22] Andrei Shleifer, Robert W. Vishny,"Liquidation Values and Debt Capacity: A Market Equilibrium Approach", The Journal of Finance, Vol. 47, No. 4 (1992), pp. 1343-1366

[23] Jeremy Stein,"Prices and Trading Volume in the Housing Market: A Model with DownPayment Effects", The Quarterly Journal of Economics, Vol. 110, No. 2 (1995), pp. $379-406$

[24] Yeneng Sun and Yongchao Zhang,"Individual risk and Lebesgue Extension Without Aggregate Uncertainty", Journal of Economic Theory, forthcoming 
[25] Robert Townsend, "Optimal Contracts and Competitive Markets with Costly State Verification", Journal of Economic Theory, Vol. 21, No. 2 (1979), pp. 265-293

[26] Stephen Williamson,"Costly Monitoring, Loan Contracts, and Equilibrium Credit Rationing", The Quarterly Journal of Economics, Vol. 102, No. 1 (1987), pp. 135-145 


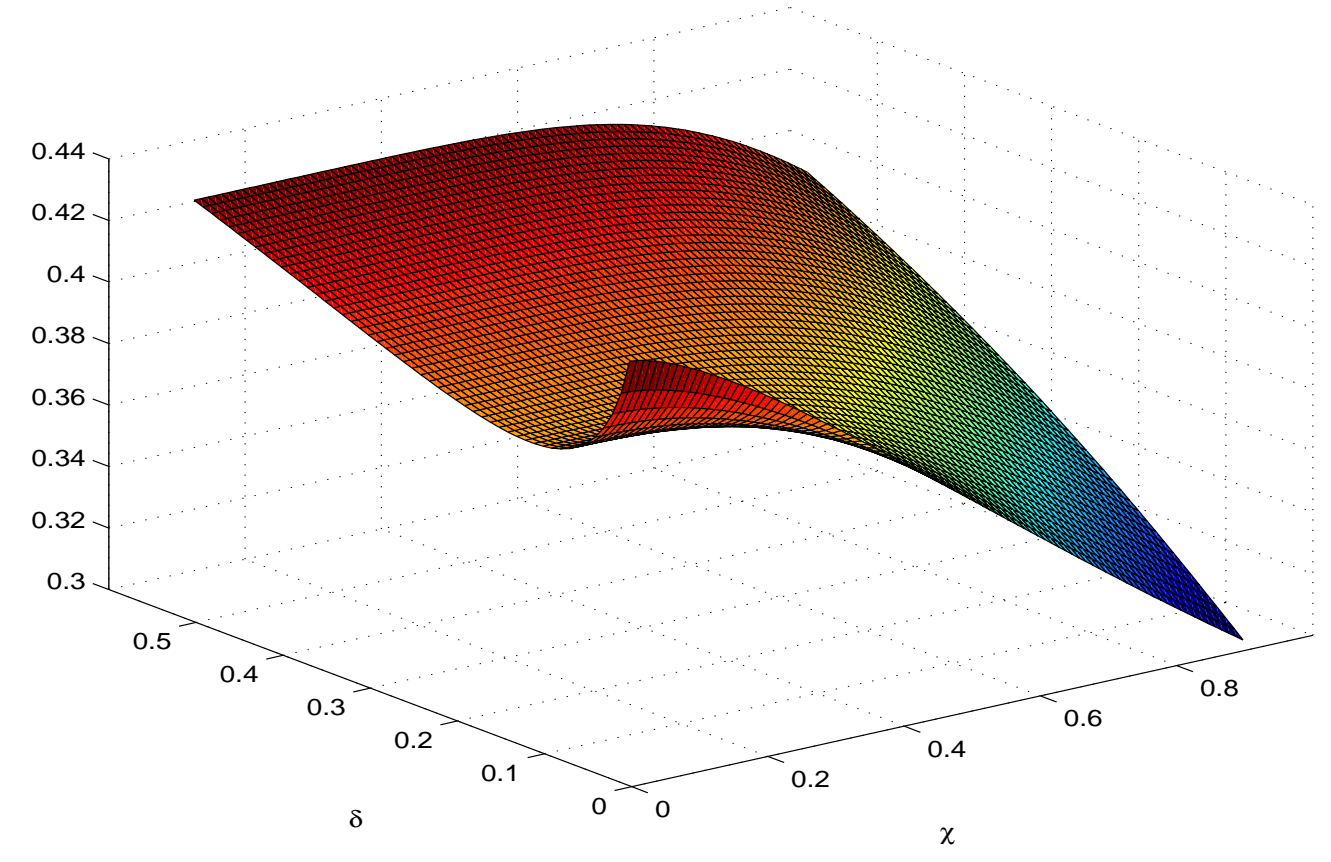

Figure 1. Loan-to-income ratio for $r=2 \%, \sigma=20 \%$, and $\lambda=15 \%$.

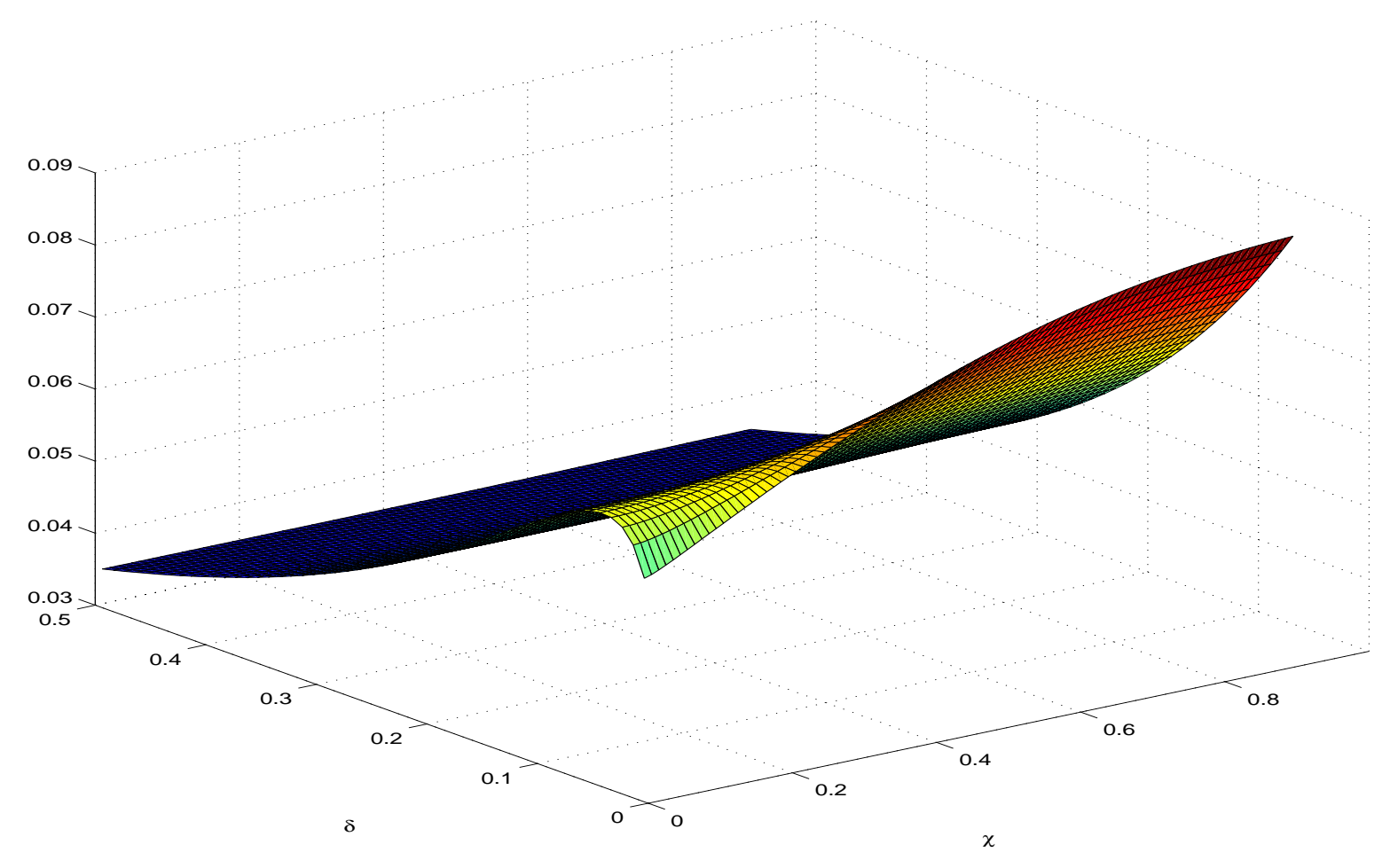

Figure 2. Default intensity for $r=2 \%, \sigma=20 \%$, and $\lambda=15 \%$. 


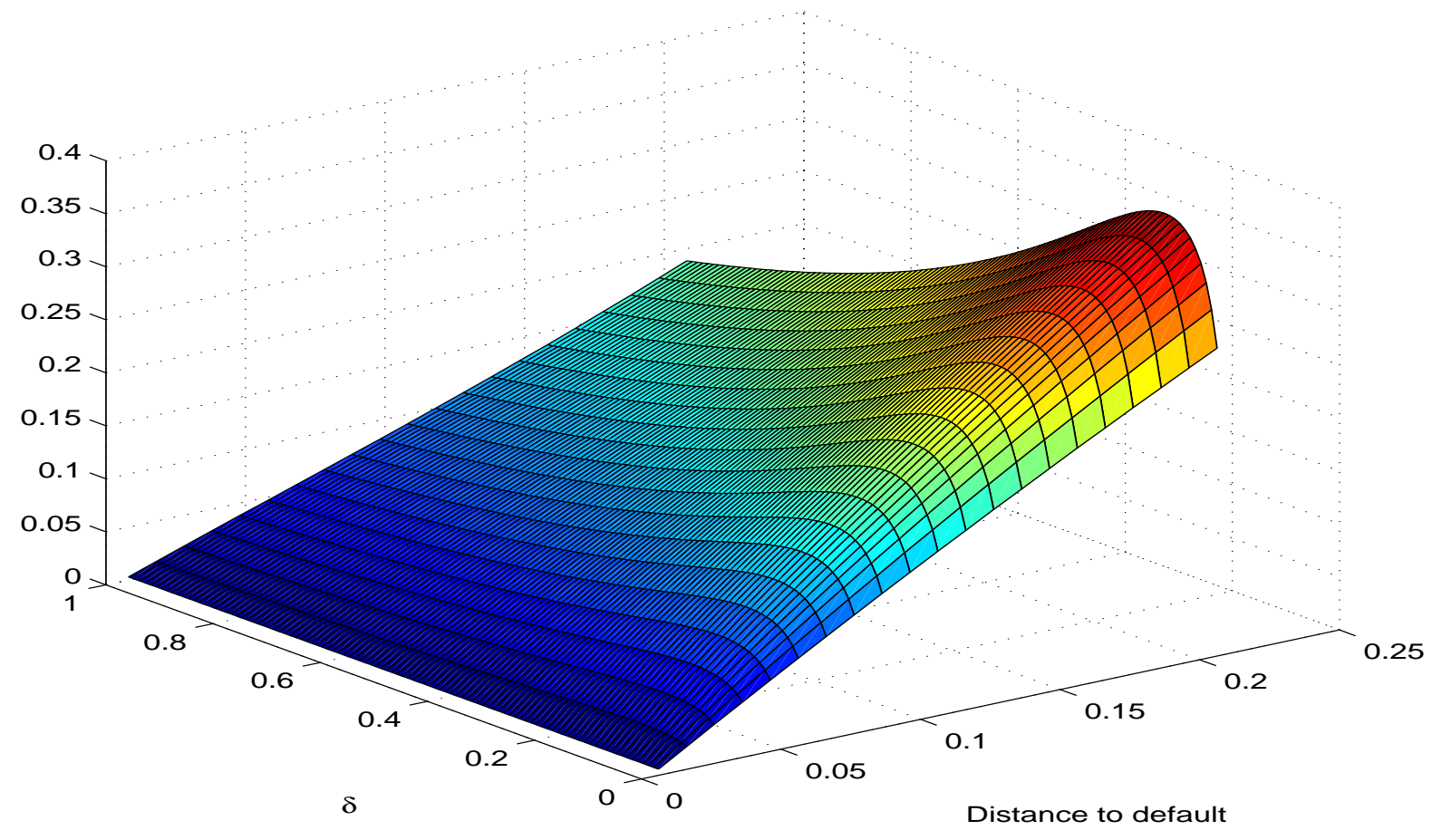

Figure 3. Density of distances to default between $0 \%$ and $25 \%$ for $r=2 \%$, $\sigma=20 \%$, and $\lambda=15 \%$.

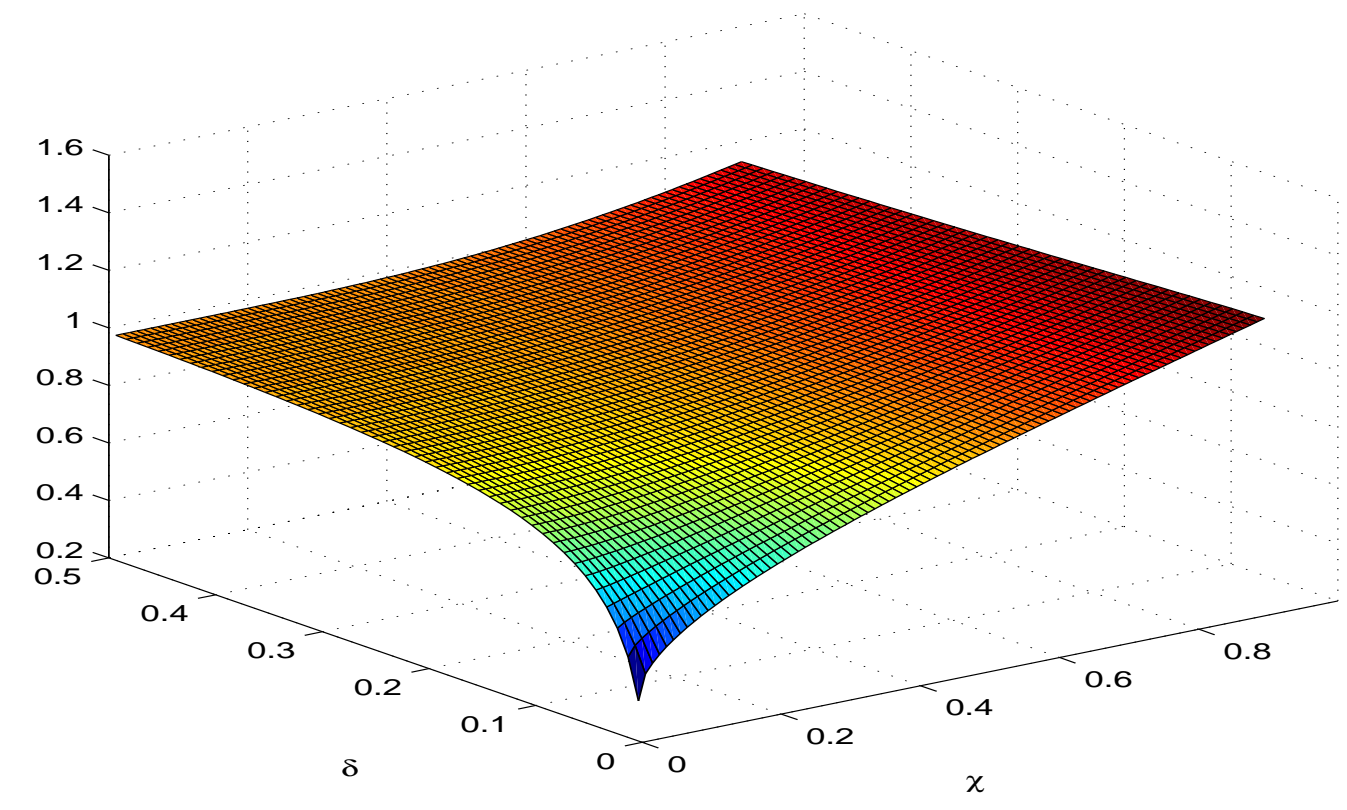

Figure 4. Income in the market for $r=2 \%, \sigma=20 \%$, and $\lambda=15 \%$. 


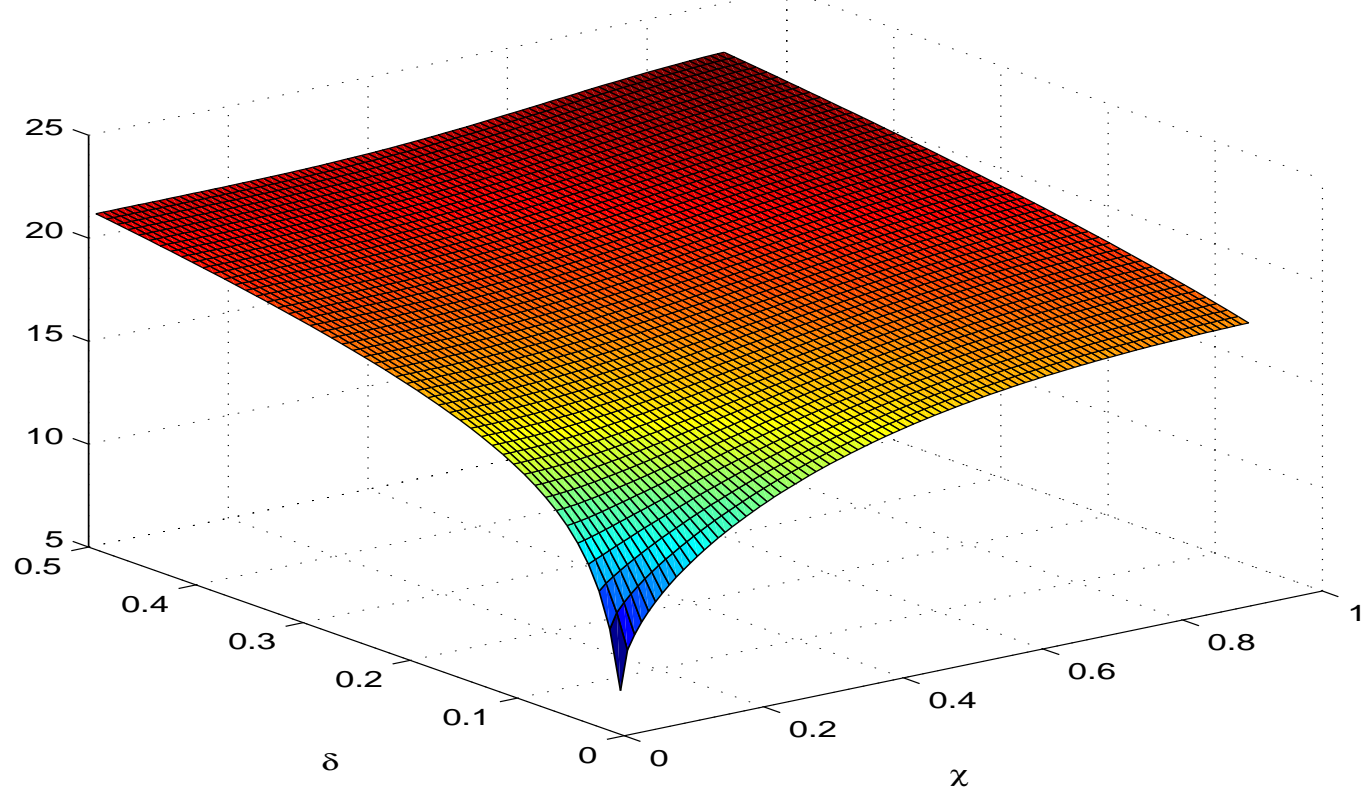

Figure 5. Aggregate lending per unit of time for $r=2 \%, \sigma=20 \%$, and $\lambda=15 \%$.

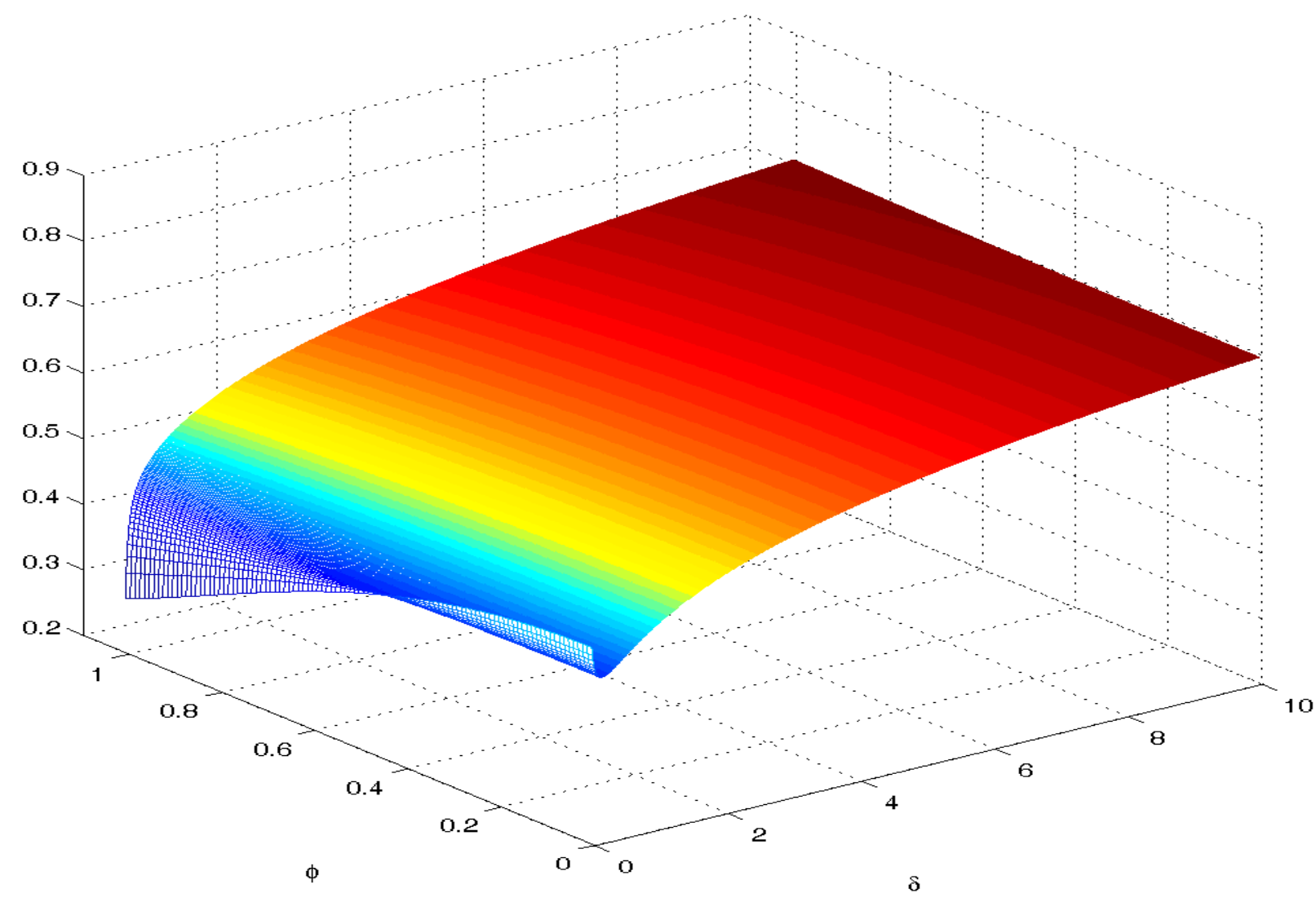

Figure 6. Loan-to-income ratio for $r=2 \%, \sigma=20 \%$, and $\lambda=15 \%$. 


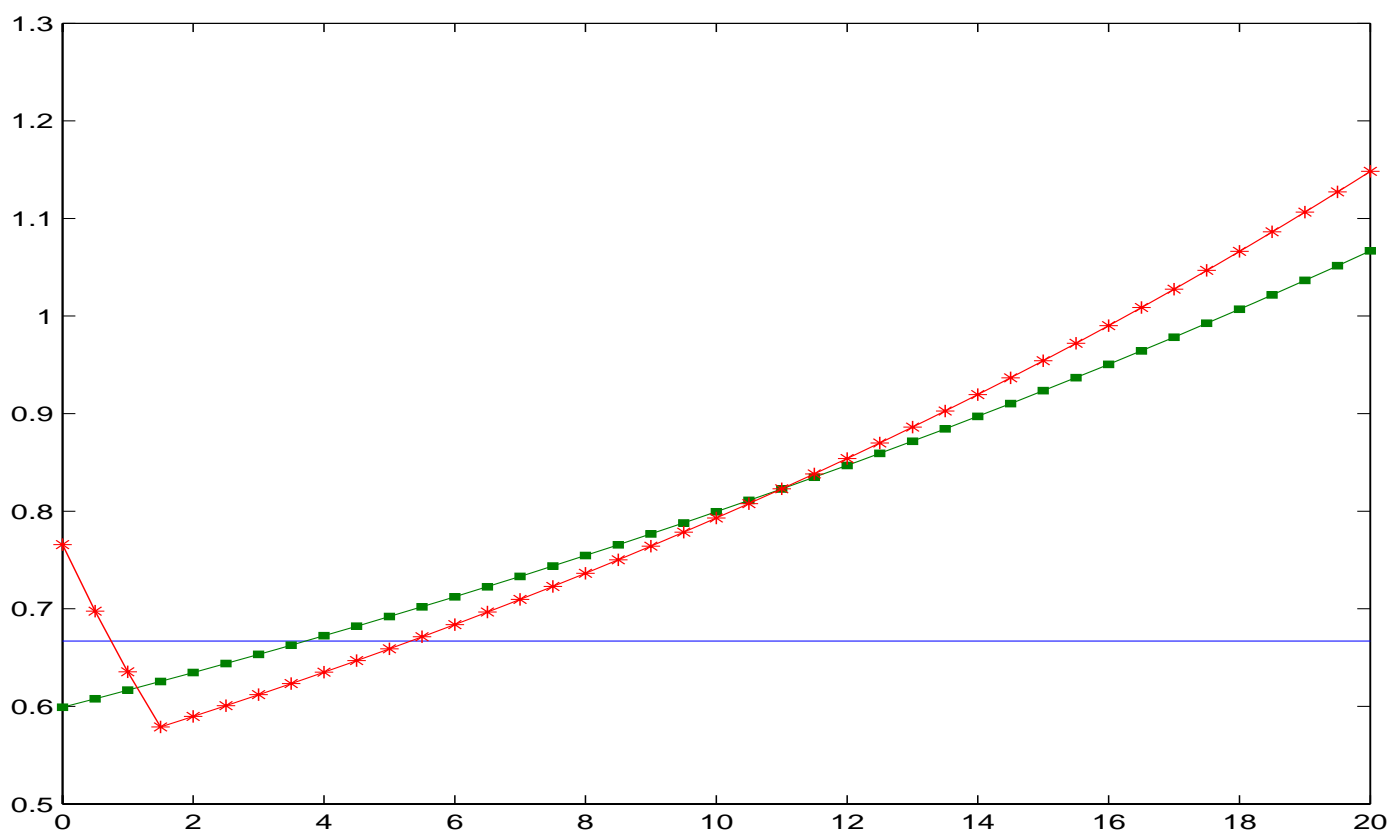

Figure 7. Optimal repayment schedules for $r=2 \%, \sigma=20 \%, \delta=5 \%$, and $\lambda=15 \%$.

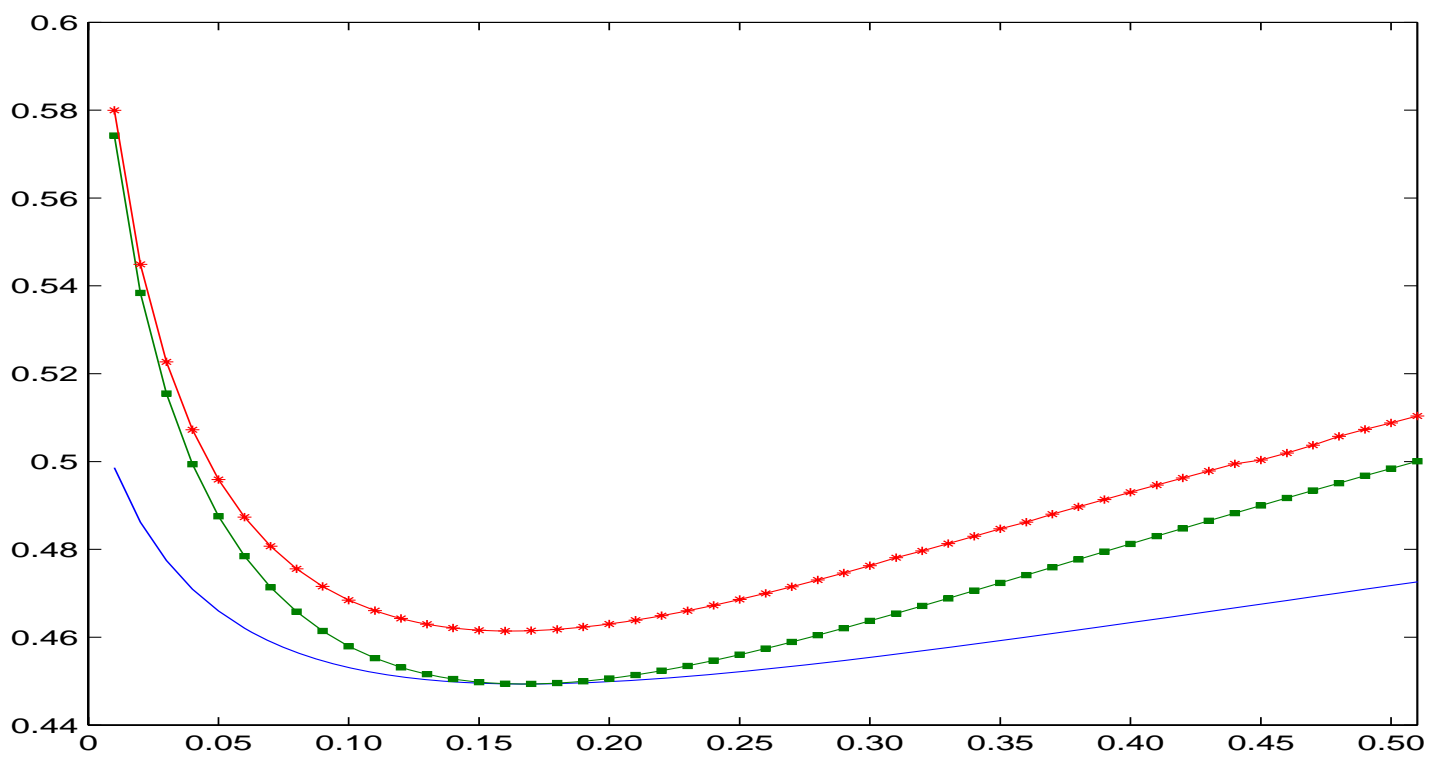

Figure 8. Loan-to-income ratio for optimal fixed, log-linear, and piecewise loglinear repayment schedules for $r=2 \%, \sigma=20 \%$, and $\lambda=15 \%$ as a function of $\delta$. 